\title{
MPPT Schemes for PV System under Normal and Partial Shading Condition: A Review
}

\author{
Malik Sameeullah ${ }^{1 a^{*}}$ and Akhilesh Swarup $2 a$ \\ ${ }^{a}$ School of Renewable Energy and Efficiency, NIT Kurukshetra, India \\ ${ }^{b}$ Department of Electrical Engineering, NIT Kurukshetra, India
}

\begin{abstract}
The photovoltaic system is one of the renewable energy device, which directly converts solar radiation into electricity. The I-V characteristics of PV system are nonlinear in nature and under variable Irradiance and temperature, PV system has a single operating point where the power output is maximum, known as Maximum Power Point (MPP) and the point varies on changes in atmospheric conditions and electrical load. Maximum Power Point Tracker (MPPT) is used to track MPP of solar PV system for maximum efficiency operation. The various MPPT techniques together with implementation are reported in literature. In order to choose the best technique based upon the requirements, comprehensive and comparative study should be available. The aim of this paper is to present a comprehensive review of various MPPT techniques for uniform insolation and partial shading conditions. Furthermore, the comparison of practically accepted and widely used techniques has been made based on features, such as control strategy, type of circuitry, number of control variables and cost. This review work provides a quick analysis and design help for PV systems.
\end{abstract}

Keywords: Renewable Energy System, Solar Photovoltaic, Solar Power Conversion, Maximum Power Point Tracking, Partial Shading, Global MPPT

Article History: Received March 14, 2016; Received in revised form June 26 $6^{\text {th }} 2016$; Accepted July 1 ${ }^{\text {st }} 2016$; Available online

How to Cite This Article: Sameeullah, M. and Swarup, A. (2016). MPPT Schemes for PV System under Normal and Partial Shading Condition: A Review. Int. Journal of Renewable Energy Development, 5(2), 79-94.

http://dx.doi.org/10.14710/ijred.5.2.79-94

\section{Introduction}

With an increase in energy demand day by day and depletion of conventional energy sources, the governments and energy agencies all over the world are looking toward an alternative forms of energy, which is sustainable and renewable in nature. Among the available alternative energy, the PV energy is one of the promising alternatives as it is freely present, inexhaustible, noise free and clean form of energy (Kumar et al. 2014). The demand of grid connected and standalone PV system is increased due to reduction in solar PV panel cost and increased in power electronics circuit efficiency. However, the conversion efficiency of the most efficient PV panel is still in the range of 1128\% (NREL 2014), and it is further degraded, if the PV system is not operated properly. For any Irradiance and temperature condition, there is only one point where available power is maximum. This point is known as maximum power point (MPP) and techniques used to operate PV system at MPP is known as MPPT. In order to extract each bit of power, an efficient MPPT technique is essential, which operate properly under different environmental condition.

Several MPPT techniques and circuit configuration methods for improving the efficiency of PV system have been reported in the literature. Many technical papers discussed the MPPT techniques, but most of the review papers mainly considered the MPPT methods for normal radiation condition. Besides the normal MPPT schemes, the important and practically viable MPPT techniques have been presented in this paper. The MPPT techniques under Partial Shading have also been analyzed for maximizing the efficiency of PV system. This review work presents guidelines for researcher and practitioners to select appropriate MPPT control scheme from a wide range of available technology.

*Malik Sameeullah, Ph: +91-9896009854

Email: malik.sameeullah@gmail.com 
This paper is organized in six sections. Section 2 consists of brief detail of PV model and MPPT concept. The various MPPT technologies for normal Irradiance are discussed in section 3 . In section 4 , some of the famous and widely used techniques to track MPP under partial shading are discussed. The MPPT techniques have been compared in section 5 and brief concluding remarks are presented in section 6 .

\section{Solar Photovoltaic System}

A PV cell is basically a p-n junction semiconductor which converts parts of solar radiation into electricity (Villalva et al. 2009). Typical voltage and current of PV cell are very low, so multiple cells are connected in series and parallel form to increase the rating and known as a module. Similarly, number of PV module connected in series and parallel fashion, is known as PV array. The PV panel is a radiation control current source in parallel with diode and loss resistance. A single diode mathematical model of PV module is shown in Fig. 1. The I-V characteristic of PV module is given by Equation 1 , which considers the effect of shunt and series resistance (Villalva et al. 2009).

$$
I=I_{P V}-I_{o}\left(\exp \left(\frac{q\left(V+R_{s} I\right)}{a N_{s} k T}\right)-1\right)-\frac{V+R_{s} I}{R_{p h}}
$$

where $\mathrm{IPV}_{\mathrm{PV}}$ is the photovoltaic current, $\mathrm{I}_{\mathrm{o}}$ is the saturation current of the diode, $\mathrm{q}$ is the electron charge, $\mathrm{k}$ is the Boltzmann constant $\left(1.38 \times 10^{-23} \mathrm{~J} / \mathrm{K}\right), \mathrm{T}$ is an absolute temperature of PV cell and (a) is the ideality factor of diode, $R_{s}$ is the series resistance and $R_{p h}$ is the shunt resistance of PV module. In Equation (1), $\mathrm{N}_{\mathrm{s}}$ is the cells connected in series and $\mathrm{aN}_{\mathrm{s}} \mathrm{Kt} / \mathrm{q}$ is the thermal voltage $\left(V_{t}\right)$ of the module.

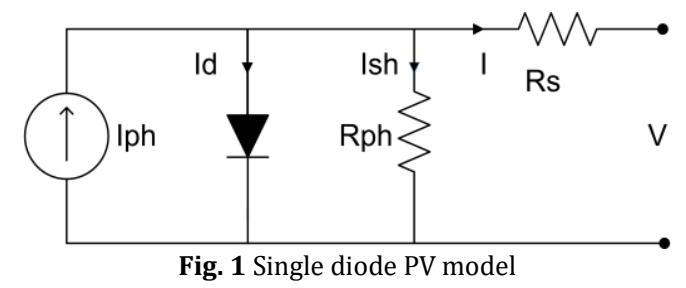

For any PV module, there are five unknown parameters $-R_{P}, R_{s}, a, I P V$ and $I_{o}$. The datasheet of PV module is used to calculate the unknown parameters directly or indirectly. A various iterative and direct methods of calculation are available for accurate calculation of parameters (Lobera and Valkealahti 2014; Ishaque et al. 2011; Subidhi and Pradhan 2012). Under Standard Test Condition (Irradiance: $1000 \mathrm{~W} /$ $\mathrm{m}^{2}$, cell temperature: $27^{\circ} \mathrm{C}$ ), IPv is approximately equal to short circuit current $\left(\mathrm{I}_{\mathrm{scn}}\right)$. The IPv depends upon solar irradiance and temperature. Photo current is given by Lobera and Valkealathi (2014):

$$
\begin{aligned}
& I_{P V}=\left(I_{P V n}+K_{I} \Delta T\right) \frac{G}{G_{n}} \\
& I_{P V}=\left(\left(I_{s c n} \frac{R_{p h}+R_{s}}{R_{p h}}\right)+K_{I} \Delta T\right) \frac{G}{G_{n}}
\end{aligned}
$$

where $\mathrm{K}_{\mathrm{I}}$ is the temperature coefficient of short circuit current and $\Delta \mathrm{T}$ is the difference between actual temperature and nominal temperature. Diode saturation current is calculated by solving (1) and given by Equation (4).

$$
\begin{aligned}
& I_{o}=\frac{I_{s c}}{\exp \left(V_{o c} / V_{t}\right)-1} \\
& I_{o}=\frac{I_{s c n}+K_{I} \Delta T}{\exp \left(\left(V_{o c n}+K_{V} \Delta T\right) / V_{t}\right)-1}
\end{aligned}
$$

where $\mathrm{K}_{\mathrm{v}}$ is the temperature coefficient of open circuit voltage. The $\mathrm{P}-\mathrm{V}$ characteristics of $\mathrm{PV}$ module under different Irradiance and temperature are shown in Fig. 2. Fig. 2 illustrates that irradiance affect the short circuit current with little effect on open circuit voltage. Similarly, the open circuit voltage starts increasing with decrease in temperature and there is little or no change in short circuit current (Lobera and Valkealathi 2014; Ishaque et al. 2011).

The Fig. 3 shows the points of maximum power at different irradiance. The blue line represents the resistive load line. It shows that if fixed resistance is connected across the PV array then point of operation ( $A^{\prime}$ or $B^{\prime}$ or $C^{\prime}$ or $D^{\prime}$ ) is depends upon the load resistance and Irradiance level. For MPP operation, the optimal resistance needs to connect across the PV array. Generally, the load or battery rating is fixed, and environment condition varies rapidly. The MPPT is used to operate PV system at point A, B, C or D. The MPPT techniques make the use of algorithm and electronic circuit for maximum power extraction. The MPPT works to match the impedance of load and PV system. The impedance matching is carried out by using DC-DC converter, whose duty cycle is adjusted in a manner to make the value of apparent load across the PV array, equivalent to optimal load.
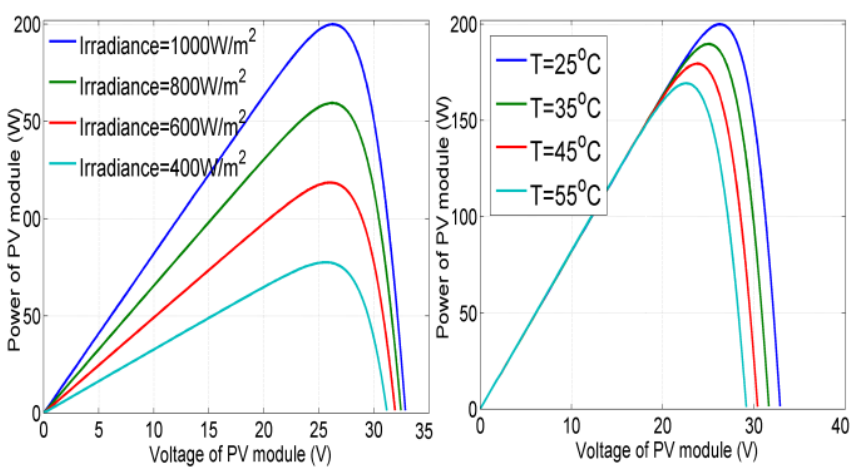

Fig. 2 P-V characterics of photovoltaic panel $(200 \mathrm{~W})$ at different Irradiance and temperature 


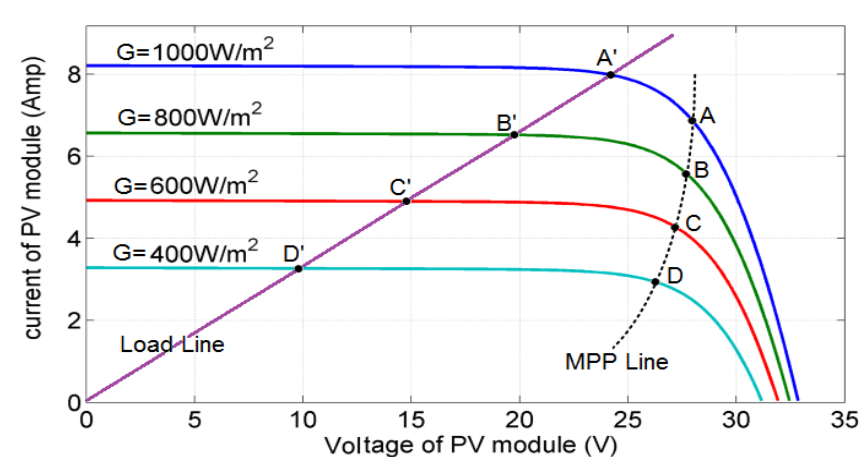

Fig. 3 Demonstration of MPP line and load line on the P-V curve

\section{MPPT Schemes for Normal Radiation}

\subsection{Curve Fitting Technique}

PV module has a similar pattern of P-V and P-I curve for different Irradiance value. A P-V curve is nonlinear in nature, and power can be given by polynomial function of voltage (Leedy and Garcia 2013; Khatib et al. 2010). The approximate equation can be found out easily by hit and trial method or using iteration method. The Power $\mathrm{P}$ in terms of $\mathrm{V}$ is given by Equation (6).

$$
P=M_{4} V^{4}+M_{3} V^{3}+M_{2} V^{2}+M_{1} V+M_{0}
$$

where $M_{4}, M_{3}, M_{2}, M_{1}$ and $M_{0}$ are constant and have different value for different atmospheric condition.

$$
\frac{d P}{d V}=4 M_{4} V^{3}+3 M_{3} V^{2}+2 M_{2} V+M_{1}
$$

To find out the $\mathrm{V}_{\text {mpp }}$ (voltage at MPP), equate $\mathrm{dP} / \mathrm{dV}$ equal to zero. For better result, Coefficients of $P=f(V)$ are calculated at different irradiance and temperature \& arrange them in the form of lookup table.

\subsection{Current Fraction Technique}

At a given Irradiance and temperature, there is a fixed MPP ( $\left.V_{m p p}, I_{m p p}\right)$. The Fig. 4 shows the linear relationship plot between $\mathrm{I}_{\mathrm{mpp}}$ and $\mathrm{I}_{\mathrm{sc}}$.

$$
I_{m p p}=K_{s c} I_{s c}
$$

Equation (8) shows a relationship between short circuit current and MPP current (Masoum et al. 2002). $\mathrm{K}_{s c}$ is called the current factor and its value depends upon the type of material use for PV manufacturing. Generally, $\mathrm{K}_{\mathrm{sc}}$ is equal to 0.86 for $\mathrm{Si} \mathrm{PV}$ module.

\subsection{Voltage Fraction Technique}

There is a linear relationship between $V_{\text {oc }}$ and $V_{\text {mpp }}$ for different Irradiance and temperature (Ahmed 2010; Adly et al. 2011). A simple and cost effective MPPT can be designed by using this technique.

$$
V_{m p p}=K_{o c} V_{o c}
$$
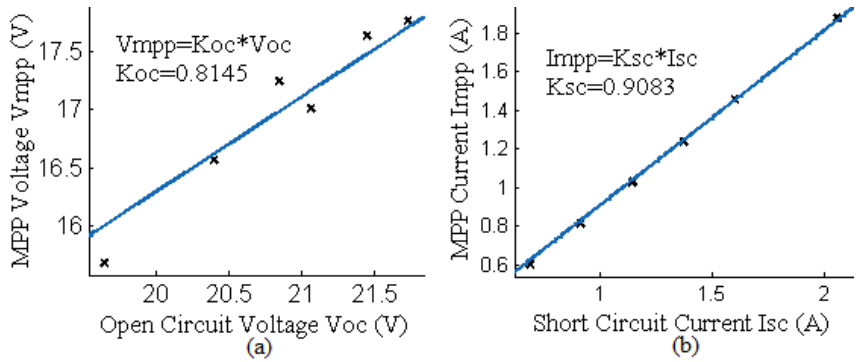

Fig. 4 (a) a plot between MPP voltage and open circuit voltage, (b) plot between MPP current and short circuit current.

where $\mathrm{K}_{\mathrm{oc}}$ is a voltage factor and lies in a range between 0.72 to 0.92 . Voltage fluctuation and unreliable output are the major drawback of this technique. In this technique, load is open circuited for a fraction of second to measure $V_{\text {oc }}$ and then relation of Equation (9) is used to find $V_{\text {mpp. }}$.

\subsection{Lookup Table Based MPPT Technique}

In this control technique, MPPs are stored in the memory by rigorous training of the system at different environmental conditions (Piao et al. 2013; Altas and Sharaf 1996). During the operation, a lookup table is used to find out the approximate optimal operating point. The Fig. 5 shows the schematic of lookup table based MPPT.

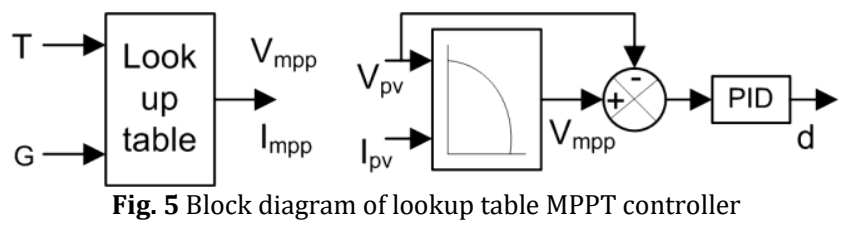

\subsection{Single Stage Control Technique}

A single stage control (SSC) is a nonlinear control technique which uses inverter to integrate PV array to AC circuit (Mastromauro et al. 2012; Chen and Smadley 2004). A single stage operation causes reduction in power loss due to multiple conversion steps. The Fig. 6 shows the block diagram of SSC using analog controller. The objective of the inverter is to force output current $\left(\mathrm{I}_{0}\right)$ to follow grid voltage. The output power at grid side and PV array output power are given by Equation (10) and (11) respectively.

$$
P_{o}=V_{o} I_{o}=\frac{V_{o}^{2}}{R_{g}}\left(K-\frac{V_{m}}{V_{g}}\right)
$$

$P_{g}=V_{g} I_{g}=V_{g}\left(I_{P V}-I_{o}\left(\exp \left(\frac{q\left(V+R_{s} I\right)}{a N_{s} k T}\right)-1\right)-\frac{V+R_{S} I}{R_{p h}}\right)$

The $\mathrm{P}_{\mathrm{o}}$ value is adjusted by adjusting $\mathrm{I}_{\mathrm{o}}$ in given range and at MPP, $\mathrm{P}_{\mathrm{g}} \approx \mathrm{P}_{0}$ achieved. By using suitable value of $R_{1}$ and $C_{1}$, operating point approaches the actual MPP with an acceptable accuracy. 


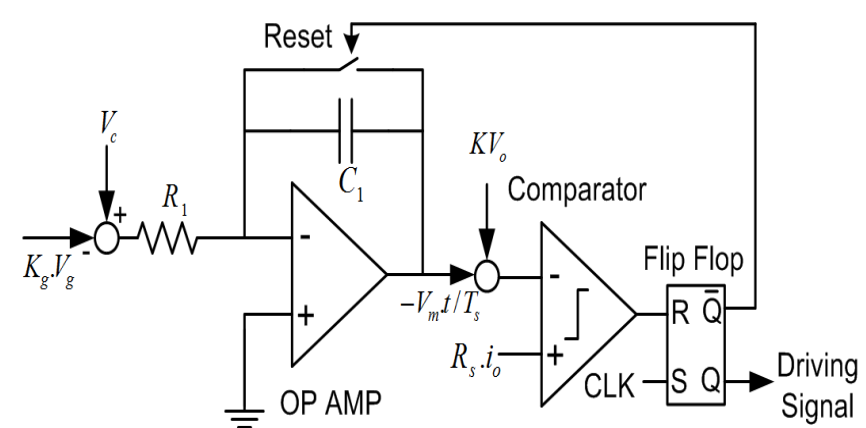

Fig. 6 Analog single stage control circuit for power optimization (Chen et al. 2004)

\subsection{Current / Voltage Feedback Technique}

This technique is used with simple DC-DC converter to maintain the fixed output voltage and to extract maximum power. The module output current (voltage) is compared with reference current (voltage) and generates error signal (Karanjkar et al. 2013). Main building block of feedback technique is PID controller, which uses error signal to generate the desired duty cycle. A proper tuning of PID is essential for better performance. The Fig. 7 shows the simple voltage feedback MPPT controller.

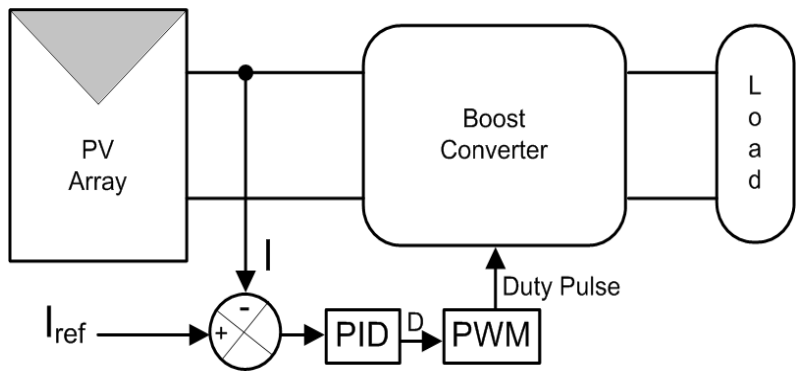

Fig. 7 Current feedback methodology for MPPT tracking

\subsection{Perturbation and Observation (P\&O) Technique}

The P\&O is a most widely used MPPT technique (Hua et al. 1998; Jie et al. 2012). As the name suggest, first it perturbs the variable either voltage or current and then observes the optimization quantity $\mathrm{P}$ (Power). Based upon the response, the controller either increase or decrease the value of V or I. Fig. 8 shows the algorithm of $\mathrm{P} \& 0$ controller. In this method, a controller measures the value of $V_{1}, I_{1}$ and calculates the corresponding power $\mathrm{P}_{1}$. Now, controller changes the reference voltage by changing the duty cycle of the dc-dc converter in one direction and check corresponding $\mathrm{V}_{2}, \mathrm{I}_{2}$ and $\mathrm{P}_{2}$. If $\mathrm{P}_{2}$ is greater than $\mathrm{P}_{1}$, then direction of perturbation is correct, otherwise change the direction of $\Delta \mathrm{d}$. At maximum power point, $\mathrm{dP} / \mathrm{dV}$ is approximately equal to zero. However in practical, the point of $\mathrm{V}_{\mathrm{mpp}}$ is hard to calculate and operating point oscillates near MPP. To reduce oscillation near MPP, $\Delta \mathrm{d}$ must be as small as possible, but it increases the tracking time. So, it is essential to chose the optimal step size of duty cycle (d).

\subsection{Incremental Conductance (INC) Technique}

The INC MPPT is an improved form of P\&O MPPT (Safari and Maekhilef 2011). It reduces the effect of oscillation at MPP and has better control as compare to P\&O (Sera et al. 2013; Kajaer 2013). It compares the instantaneous $(\mathrm{I} / \mathrm{V})$ and incremental $(\mathrm{dI} / \mathrm{dV})$ conductance. The $\mathrm{dP} / \mathrm{dV}$ is given as:

$$
\begin{aligned}
& \frac{d P}{d V}=\frac{d(V I)}{d V} \mid I_{m p p}, V_{m p p}=0 \\
& \frac{d P}{d V}=\frac{d(V I)}{d V}=I+V \frac{d I}{d V}
\end{aligned}
$$

$\frac{1}{V} \frac{d P}{d V} \mid m p p=\frac{I}{V}+\frac{d I}{d V}=0$

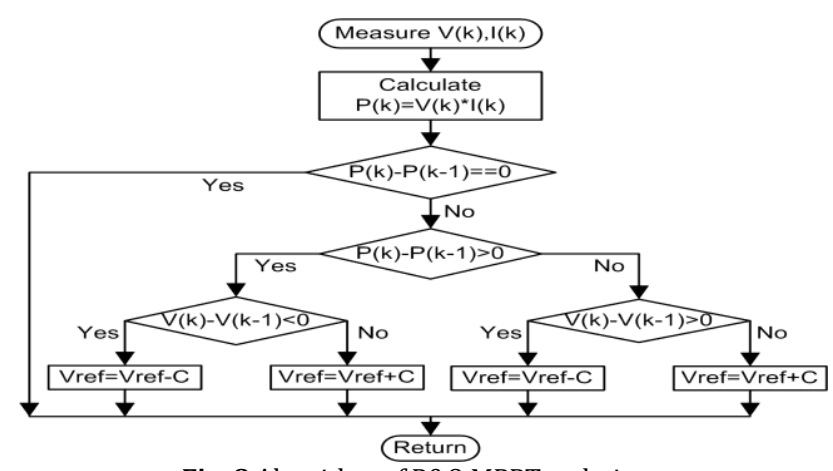

Fig. 8 Algorithm of P\&O MPPT technique

In actual, $\mathrm{dP} / \mathrm{dV}=0$ occurs rarely in practical implementation, and small error is permitted in practical situation. The sensitivity and oscillation at operating point is depended upon the limit of allowed error e. The controller changes the duty cycle of the converter based on the conditions of Equation (15).

$\frac{d P}{d V}=\left\{\begin{array}{l}=e, I / V=-d I / d V, \text { no change } \\ >e, I / V>-d I / d V, \text { increase voltage } \\ <e, I / V<-d I / d V, \text { decrease voltage }\end{array}\right.$

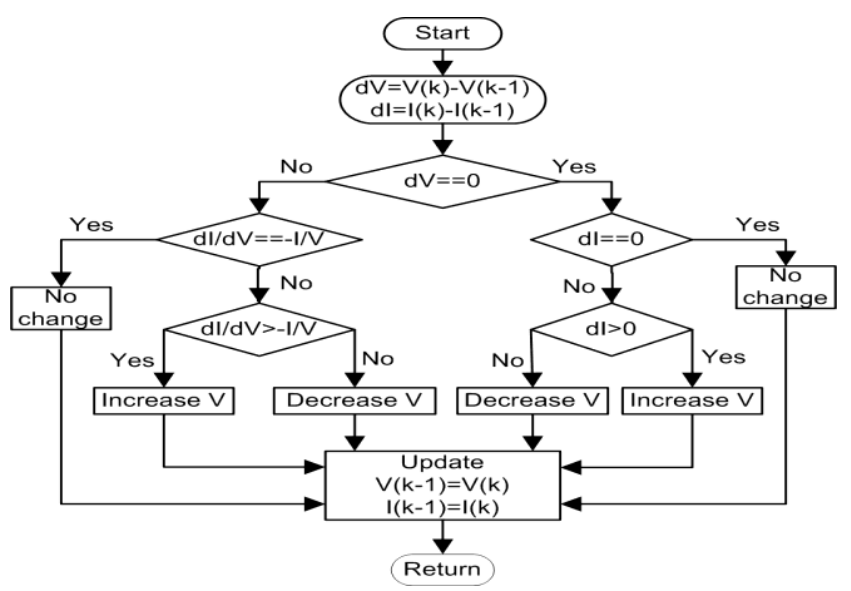

Fig. 9 Algorithm of Incremental Conductance MPPT technique 
The algorithm of INC is shown in Fig. 9. The INC controller is as efficient as $\mathrm{P} \& 0$, but it need costly controller.

\subsection{Parasitic Capacitance Technique}

The Parasitic capacitance technique is a more refined form of the incremental conductance method that takes consideration of parasitic capacitance of PV array (Hohm and Roop 2002; Brambilla et al. 1999). In the actual PV module, the effect of parasitic capacitance is calculated by the current $\mathrm{i}_{\mathrm{c}}(\mathrm{t})=\mathrm{C}_{\mathrm{p}}{ }^{*} \mathrm{dV} / \mathrm{dt}$ and the actual output current of PV module is given by Equation (16) (Hohm and Roop 2000).

$I=I_{P V}-I_{o}\left(\exp \left(\frac{q\left(V+R_{s} I\right)}{a N_{s} k T}\right)-1\right)-\frac{V+R_{s} I}{R_{p h}}+C_{p} \frac{d V}{d t}$

Equation (16) can be rewritten as

$$
I=f(V)+C_{p} \frac{d V}{d t}
$$

Power output from the PV panel is given as:

$$
P=\left(f(V)+C_{p} \frac{d V}{d t}\right) V
$$

At MPP, $\mathrm{dP} / \mathrm{Dv}=0$ and condition of MPP is obtained by calculating differential of Equation (18) with respect to $\mathrm{V}$.

$$
\frac{d f(V)}{d V}+C_{p}\left(\frac{\dot{V}}{V}+\frac{\ddot{V}}{\dot{V}}\right)+\frac{f(V)}{V}=0
$$

where $g_{p}=\mathrm{df}(\mathrm{V}) / \mathrm{dV}$ is a differential conductance, $\mathrm{gl}_{\mathrm{l}}=\mathrm{f}(\mathrm{V}) / \mathrm{V}$ is the adapted load conductance and $\mathrm{g}_{\mathrm{c}}$ is the incremental conductance. $g_{p}$ and $g_{c}$ have the term of first and second derivative of ripple voltage. The parasitic capacitance is modeled as a capacitor connected in parallel with the PV panel. The panels connected in parallel increase the effect of $C_{p}$ and similarly PV panels connected in series reduce the effect of capacitance. The $\mathrm{g}_{\mathrm{p}}$ of the panel is calculated by modulating the ripple of I \& $\mathrm{V}$ and given as:

$g_{p}=\frac{P_{g p}}{V_{o}^{2}}$

where $\mathrm{P}_{g p}$ is the average ripple power and $\mathrm{V}_{\mathrm{o}}$ is the average ripple voltage. The $g_{p}$ can be calculated easily by using low pass and high pass filter as shown in Fig.10. The $g_{p}$ and $g_{1}$ are compared and resulting error signal is used to track MPP.

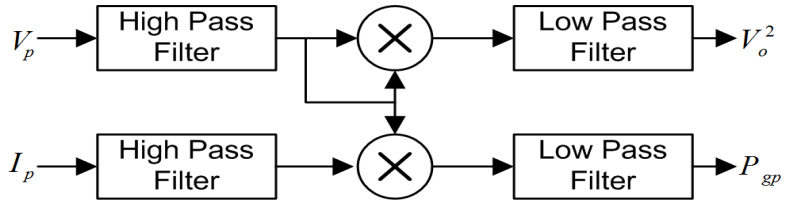

Fig. 10 The circuit block diagram for the calculation of $P_{g p}$ and $V_{o}{ }^{2}$

\subsection{Sliding Mode Control Technique}

The sliding mode control (SMC) is one of the robust nonlinear control approach technique (Mamarelis et al. 2014). It has two modes of operation: approaching mode and sliding mode. In approaching mode, the system converges to a pre-defined manifold in finite time and in sliding mode, the system state confined on the sliding surface and is driven to origin (Cabal et al. 2004). $\mathrm{A} \mathrm{dV} / \mathrm{dI}=0$ is selected as sliding surface as it is guaranteed that system state will hit the maximum power surface.

$\frac{d P}{d V}=\frac{d I^{2} R_{p v}}{d I}=I_{p v}\left(2 R_{p v}+I_{p v} \frac{d R_{p v}}{d I}\right)=0$

where $R_{p v}$ is the equivalent load at PV panel. The non trival solution of the system is $2 R_{p v}+I_{p v}\left(d R_{p v} / d I\right)=0$. Hence sliding surface is given by:

$\sigma \cong\left(2 R_{p v}+I_{p v} \frac{d R_{p v}}{d I}\right)$

The control signal for DC-DC converter can be chosen as:

$d_{\text {update }}=\left\{\begin{array}{l}d+\Delta d, \text { for } \sigma>0 \\ d-\Delta d, \text { for } \sigma<0\end{array}\right.$

The state equation of the PV model can be replaced by an average state equation by considering the weightage of state equation when switch is open as (1d ) and weightage of state equation as d, when switch is closed. The result can be written in the nonlinear time invariant system as:

$\dot{X}=f(V)+g(X) \cdot d$

The equivalent duty cycle $\mathrm{d}_{\mathrm{eq}}$ is determined from the condition:

$\dot{\sigma}=\left[\frac{d \sigma}{d X}\right]^{T} \dot{X}$

The equivalent duty cycle control is given by Equation (26).

$d=\left\{\begin{array}{ccc}1 & \text { if } & d_{e q}+k_{c} \sigma \geq 1 \\ d_{e q}+k_{c} \sigma & \text { if } & 0<d_{e q}+k_{c} \sigma<1 \\ 0 & \text { if } & d_{e q}+k_{c} \sigma \leq 0\end{array}\right.$

The SMC is compatible for a wide range of processor such as microcontroller, DSP, FPGA etc. The main limitation of SMC is a measurement of $\mathrm{V}$ and $\mathrm{I}$, as measurement of I need a state observer. 


\subsection{Fuzzy Logic Control Technique}

The Fuzzy logic controller (FLC) uses the fuzzy logics to make decisions and provides appropriate control signal (Hajighorbani et al. 2014; Abdourraziq and Rachid 2014). The FLC consists of mainly three components - fuzzification, rule base inference engine and defuzzification as shown in Fig. 11.

As shown in Fig. 11, there are two inputs - error e(k) \& change in error ce(k) and one output $-\Delta \mathrm{d}(\mathrm{k})$. The fuzzification block converts the crisp inputs to fuzzy inputs. The rule base is used to apply rules and generate fuzzy output. This fuzzy output is further converted to crisp output using defuzzification block. Generally, Mamdani block is used to generate a rule base and centre of gravity is used to generate the output of FLC.

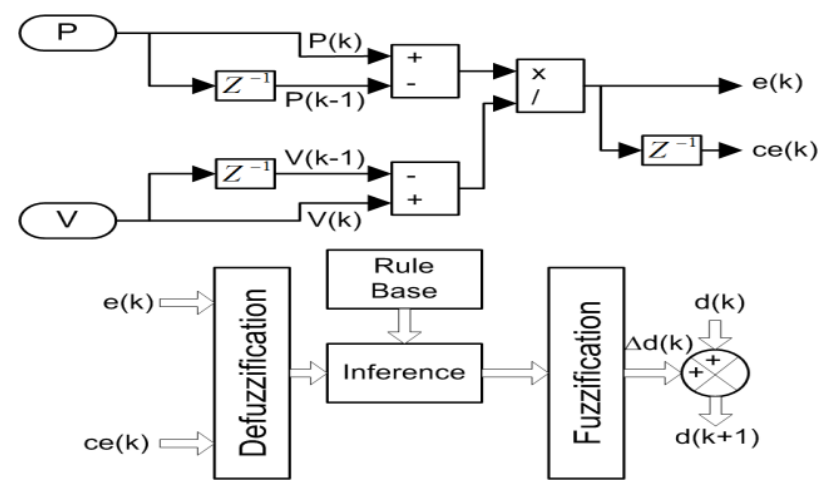

Fig. 11 Block diagram of Fuzzy Logic MPPT technique

For P\&O based FLC, e(k) is equal to $\mathrm{dP} / \mathrm{dV}$ and $\mathrm{ce}(\mathrm{k})=\mathrm{e}(\mathrm{k})-\mathrm{e}(\mathrm{k}-1)$ (Atiqi 2014). The $\mathrm{e}(\mathrm{k})$ and $\mathrm{ce}(\mathrm{k})$ is used to find out the location and direction of DC-DC converter operation. If $\mathrm{e}(\mathrm{k})$ is positive, then point of operation is left side of MPP, otherwise it is on right side of MPP. Similarly, positive or negative value of ce(k) gives the detail of tracking direction. The membership functions (MF) of input and output are shown in Fig. 12. For implementing the FLC system, a person needs to have enough experience more than the accurate technical knowledge of the model, as deciding the rule and range of MFs are important and critical section.

\subsection{Artificial Neural Network (ANN) Technique}

The ANN working is based upon the human behavior which have thousands of artificial neurons connected with weights (Kulaksiz et al. 2012; Lin et al. 2011; Farhat et al. 2013; Ocrun et al. 2013). The ANN is able to solve complex mathematical problem without computing the complex structure. Generally, ANN contains three layers - input, output and hidden layer. The generalized structure of ANN is shown in Fig. 13. For solar PV MPPT, ANN input consists of system parameters like environmental data of Irradiance and temperature, PV current and voltage, or any combinations of these. The output can be an optimal voltage value or a duty cycle signal.

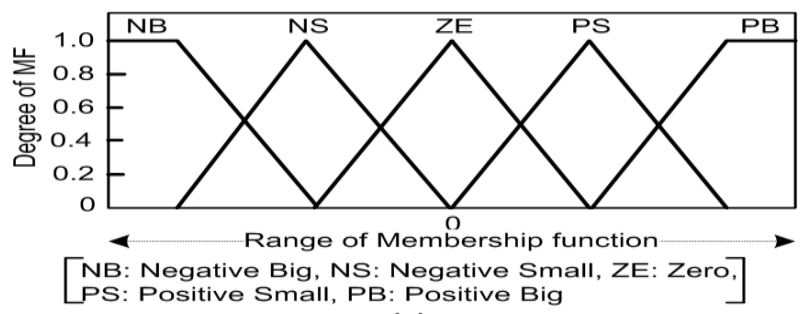

\begin{tabular}{|c|c|c|c|c|c|}
\hline CE & NB & NS & $Z E$ & $P S$ & $P B$ \\
\hline$N B$ & $Z E$ & $Z E$ & PB & PB & PB \\
\hline NS & $Z E$ & $Z E$ & PS & PS & PS \\
\hline$Z E$ & $P S$ & $Z E$ & $Z E$ & $Z E$ & NS \\
\hline PS & NS & NS & $Z E$ & $Z E$ & $Z E$ \\
\hline PB & NB & NB & $Z E$ & $Z E$ & $Z E$ \\
\hline
\end{tabular}

(b)

Fig. 12 (a) Membership function for input and output linguistic variable, (b) Fuzzy rule table for implementing MPPT

Just like a human brain, ANN needs to be trained by recognizing it a pattern of different input and output combinations. For training, the back propagation algorithm is generally used. The difference of measured output and model estimation is a weight error $\varepsilon(w)$ and it is further utilized to adjust the weights $w_{i}$ of hidden layers. After proper training and adjustment of weights, the ANN controller is able to detect MPP accurately for different Irradiance and temperature.

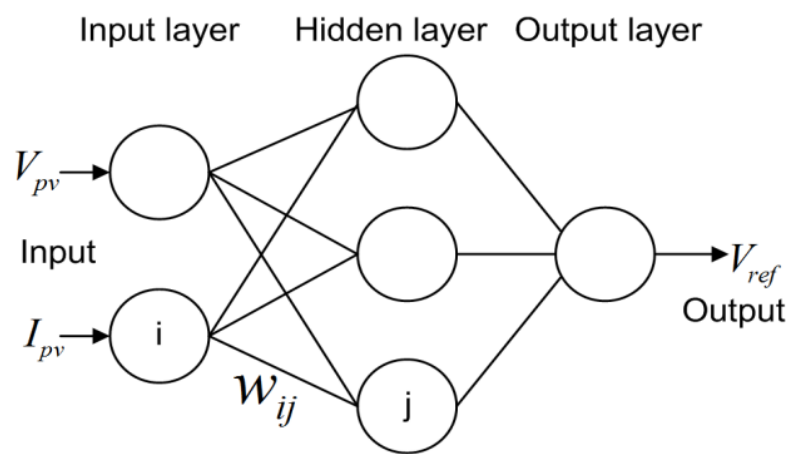

Fig. 13 Artificial Neural Network layer for MPPT (Lin et al. 2011)

\subsection{Adaptive P\&O or INC Technique}

In P\&O or INC control techniques, dynamic and steady state responses of controller is depending upon the step size of duty cycle. A large step size contributed to fast dynamic response, but it increases the steady state losses. Similarly, small step size reverses the situation. To improve the dynamic and steady state response simultaneously, adaptive INC or P\&O is used with variable step size (Kollimalla and Mishra 2014; Lee and Kim 2012; Mei et al. 2011). In this method, the step size is updated and its value lies between $\Delta \mathrm{d}_{\min }<\Delta \mathrm{d}<\Delta \mathrm{d}_{\max }$. As operating point move toward MPP, The step size of duty cycle is reduced continuously based upon some set of rule like slope of $\mathrm{dP} / \mathrm{dV}$. A adaptive P\&O - fuzzy control MPPT is proposed in Atiqi et al. (2014). 


\subsection{Hybrid MPPT Technique}

Each MPPT technique has its own advantage and disadvantage. In hybrid MPPT technique, features of two or more MPPT are used to improve the overall performance and reduce error. The hybrid adaptive P\&O MPPT is proposed in Zhang et al. (2013). In this technique, fixed voltage fraction MPPT is used to find approximate MPP and adaptive P\&O MPPT locates the exact maximum power point. By using the combination of two MPPT, reduction in operating time and steady state error is reported. Similarly, other hybrid combinations like P\&O - ANN, current friction - P\&O, current friction - fuzzy control and ANN - fuzzy control are proposed in literature (Zhang et al. 2013; Iqbal et al. 2010; Jiang et al. 2013). The performance of reported Adaptive Extremum Seeking MPPT in Xiao et al. (2013), indicates that it is able to track MPP regardless of the device and ambient changes.

\section{MPPT Schemes for Partial Shading Conditions}

The PV array is a combination of series and parallel connected PV modules and the performance of the array is depended on the individual cell characteristics. There are variation in individual cells characteristics due to mismatch loss (dust, chemical ageing, partial shading and radiation). For the series connected PV cells, the maximum current flow in the string is decided by the minimum radiation receiving cell. The partial shaded cells absorb the extra power generated by the unshaded cells and converts it into heat. Ultimately, it causes reduction in overall output power of PV array and it also degrades the life of PV panel due to internal heating (Patel and Agarwal 2008). The effect of partial shading can be eliminated by connecting a bypass diode across each module. The bypass diode provides an alternative way for excess current and increase the life cycle of the module. But the PV array with bypass diode have a complex I-V and P-V characteristics with multiple power peaks under partial shading conditions (Ding et al. 2012; Dolara et al. 2013). The 10x5 PV array with partial shading pattern is shown in Fig. 14. The plotted $\mathrm{I}-\mathrm{V}$ and P-V curve of the PV array is shown in Fig. 14. It is clear from the Fig. 14 that under partial shading, there are multiple maximum power points and the prediction of global maximum power point location is a typical task. Some of the critical observations from the Fig. 14 are listed below:

- I-V curve has multiple steps

- The location of GMPP is dependent upon the shading pattern, array configuration and Irradiation

- The MPPs are at multiple of $80 \%$ of $\mathrm{V}_{\text {oc,module }}$

- The minimum displacement between two successive MPPs is approximately $80 \%$ of $\mathrm{V}_{\text {oc,module }}$

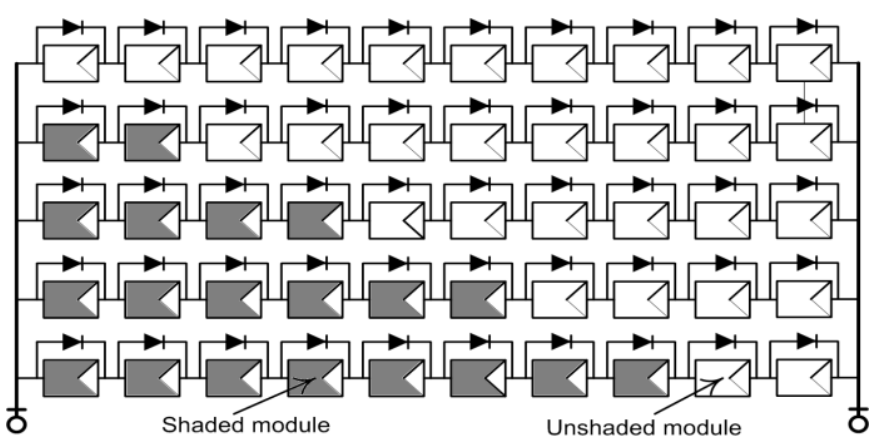

Fig. 14 Pattern of partially shaded solar PV array $(10 \times 5)$ with Irradiance of $1000 \mathrm{~W} / \mathrm{m}^{2}$ on the unshaded module and $300 \mathrm{~W} / \mathrm{m}^{2}$ on the shaded modules

The conventional MPPT controller is designed to track MPP based on some basic concept like $\mathrm{dP} / \mathrm{dV}=0$ and $P_{m p p}=f(V)$. In case of partial shading, conventional controller is not able to differentiate between local maximum power point (LMPP) and global maximum power point (GMPP) and indirectly, controller efficiency is compromised. So it needs to modify the design configuration of conventional MPPT. The different techniques for GMPP tracking with detailed discussion are explained next.

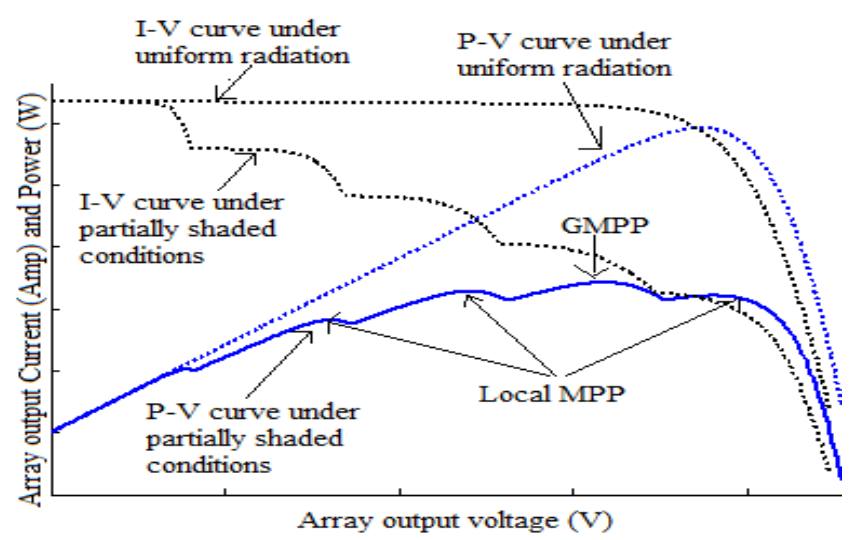

Fig. $15 \mathrm{P}-\mathrm{V}$ and I-V curve for the PV array under partially shaded condition

\subsection{Simple Power Curve Scanning Technique}

It is a simple scanning technique which scans the P-V curve from $V_{\min }$ to $V_{\max }$ and store the maximum power operating point (Koutroulis and Blaabjerg 2012). The change in Power $\left(\Delta \mathrm{P}=\mathrm{P}_{\mathrm{k}}-\mathrm{P}_{\mathrm{k}-1}\right)$ or change in slope $(\mathrm{dP} / \mathrm{dV})$ in two consecutive measurement steps is used to initiate the GMPP algorithm. If $\Delta \mathrm{P}$ is greater than $\Delta \mathrm{P}_{\text {critical, }}$ then there is a partial shading or sudden change in irradiation and the scanning of the P-V curve must start. During Scanning, the voltage of $\mathrm{PV}\left(\mathrm{V}_{\mathrm{PV}}\right)$ is continuously increased in steps from $V_{\min }$ to $V_{\max }$, given as follow:

$$
V_{P V}(k)=V_{P V}(k-1)+\Delta V_{\text {step }}
$$


where $\mathrm{V}_{\mathrm{PV}}(\mathrm{k})$ and $\mathrm{V}_{\mathrm{PV}}(\mathrm{k}-1)$ is a voltage at $(\mathrm{k})$ and $(\mathrm{k}-1)$ iteration, and $\Delta \mathrm{V}_{\text {step }}$ is a perturbation step. The size of $\Delta \mathrm{V}_{\text {step }}$ decides the scanning period of $\mathrm{P}-\mathrm{V}$ curve. But, the large perturbation size of $\Delta V_{\text {step }}$ reduces the controller ability to discriminate between Local MPP and Global MPP. After each iteration, controller compares the output power $\left(\mathrm{P}_{\mathrm{k}}\right)$ with store power. If $\left(\mathrm{P}_{\mathrm{k}}\right)$ is greater than store power, than $\mathrm{V}_{m p p}$ is updated with $\mathrm{V}_{\mathrm{PV}}(\mathrm{k})$. The algorithm of the simple scanning is shown in Fig. 16.

The scanning period of the above controller further reduce by considering the fact that the MPP of PV is at $75-80 \%$ of $V_{\text {oc. }}$ In Ding et al. (2012), the scanning is performed at predefined voltage points that is at a

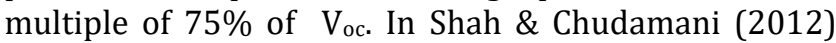
and Sobhana et al. (2013), timer based periodic scanning is also performed. It reduces the chance of the PV system to operate at Local MPP and further it increase the reliability of the controller.

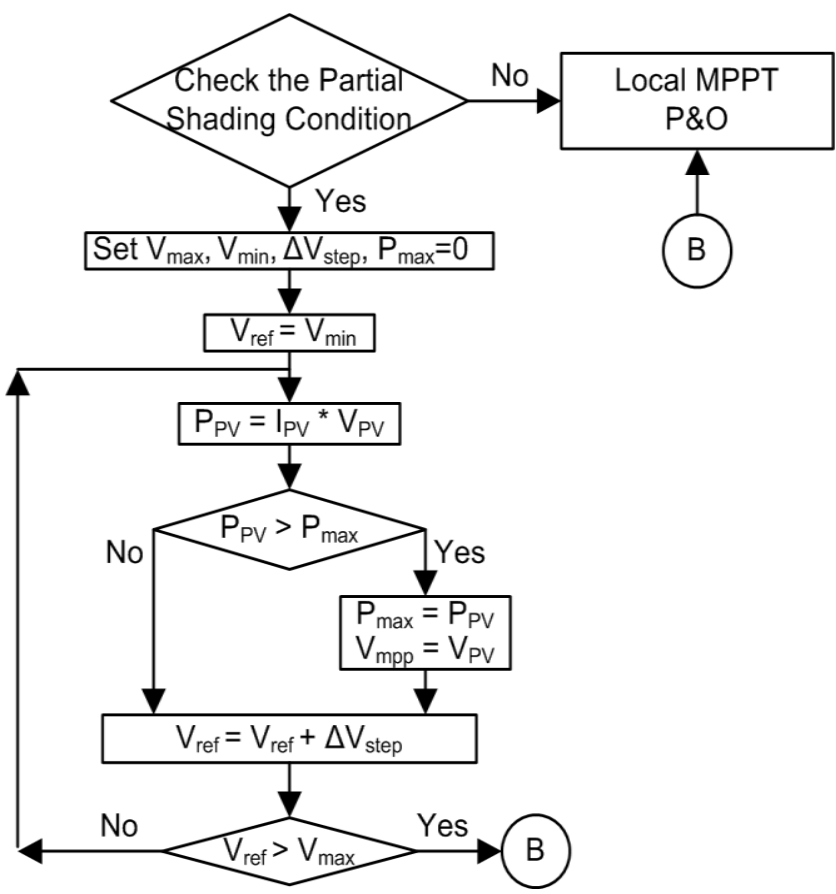

Fig. 16 GMPPT algorithm for the PV curve scanning

\subsection{Power Curve Slope Detection Technique}

The Power Slope technique is a modified form of the continuous search scheme. In this method, the sign of $\mathrm{dP} / \mathrm{dV}$ is checked at different operating point and it is used to judge the Local MPP. In Patel and Agarwal (2008), the simple P\&O method is used to track MPP and a power slope subroutine is used to detect GMPP under partial shading. As shown in Fig. 17, the presence of any LMPP on the left side of the current Maximum is detected by change in slope $(\mathrm{dP} / \mathrm{dV})$ sign at two consecutive points, from positive to negative. Similarly, the right side LMPP is indicated by the change in slope sign from negative to positive. The proper analysis of $\mathrm{P}$ -
$\mathrm{V}$ curve also shows that if the power available at two LMPP is less than the power at existing MPP, than existing MPP is a Global MPP. In Patel and Agarwal (2008), the search of MPPs are performed at both sides of existing MPP. If the LMPP is greater than the previous one, then the maximum power point is updated, otherwise controller terminates the current search direction and starts scanning in another direction. The above feature reduces the tracking time. The power curve technique is simple and can be easily implemented on low cost microcontroller. The hardware model has been implemented and verified by Patel and Agarwal (2008). The proper timer selection and duty step size $(\Delta \mathrm{V})$ is an essential parameter for increasing the performance and reliability of the controller.

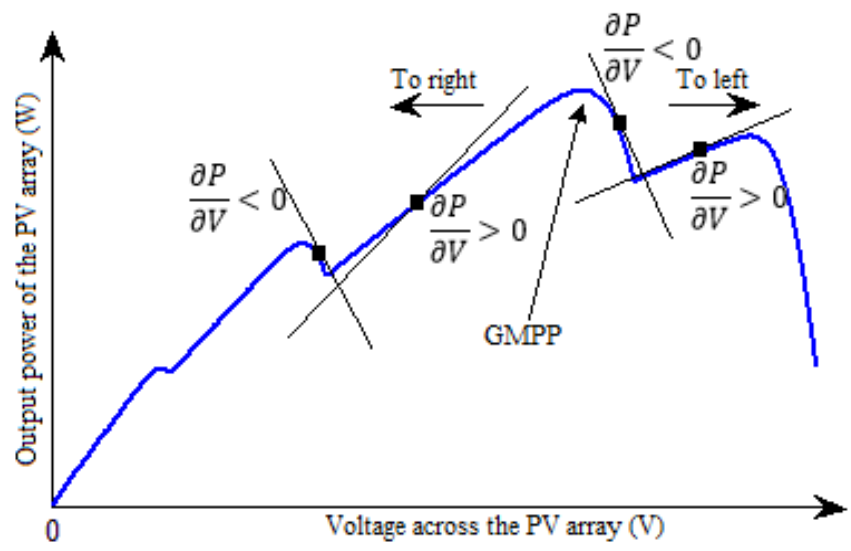

Fig. 17 Representation of change in slope sign across each local maxima

\subsection{Load Line Matching Technique}

In this technique, a load line is utilized to find the MPP. In case of partial shading, the load line with value equal to $V_{m p p} / I_{m p p}$ is computed and the system is shifted to new load line point. The $V_{m p p}$ and $I_{m p p}$ values are computed by considering the $85 \%$ of $\mathrm{V}_{\text {oc }}$ and $90 \%$ of $\mathrm{I}_{\mathrm{sc}}$ respectively. Sometime, $\mathrm{V}_{\mathrm{oc}} / \mathrm{I}_{\mathrm{sc}}$ is also considered in place of $V_{m p p} / I_{m p p}$. Analysis in Ji et al. (2011) shows that the global maximum power point is in the vicinity of the load line. As shown in Fig. 18, the operating point shifts from A to B under partial shading condition. The load line algorithm detects the partial shading and shift the operating point to C. After that, conventional MPPT is used to track the MPP D. The stepwise working procedure of the algorithm are as follow (Jun et al. 2014):

a. Measure V(n) and I(n)

b. If $\Delta \mathrm{I}>\varepsilon_{\mathrm{s}}$, then go to step $\mathrm{C}$, otherwise go to step e. ( $\varepsilon_{\mathrm{s}}$ is the threshold value for detecting shading)

c. If $\left|\frac{V(n)}{I(n)}-\frac{V_{o c}}{I_{s c}}\right|>\varepsilon_{s}$, then go to step d, otherwise go to step e. 
d. If $\frac{V(n)}{I(n)}<\frac{V_{o c}}{I_{s c}}$, increase the reference voltage by $\Delta \mathrm{V}_{\text {step, }}$ otherwise decrease it by $\Delta \mathrm{V}_{\text {step }}$.

e. Start simple MPPT for tracking local MPP.

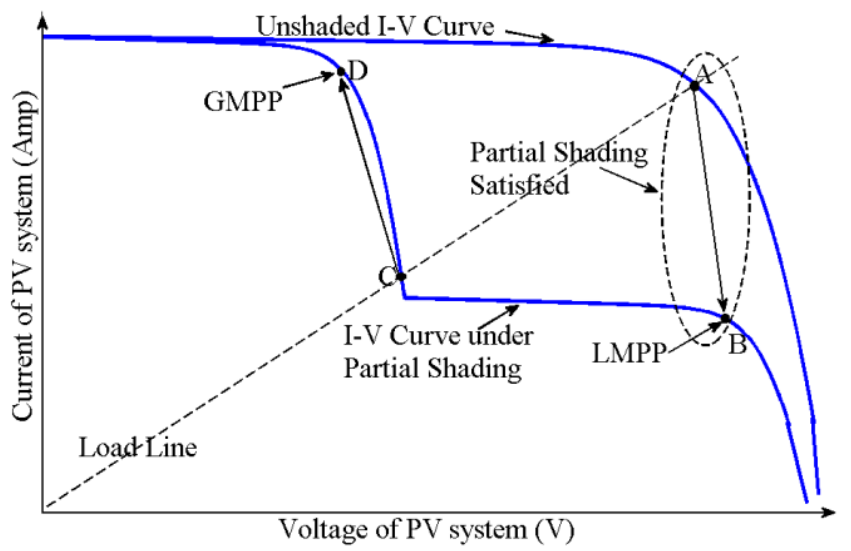

Fig. 18 Operating principal of Load Line MPPT technique

In Shah and Chudamani (2012), modified form of load line algorithm is proposed. In this algorithm, linear function is used to find the vicinity of load line. The condition of partial shading is satisfied by Equations 28 and 29.

$$
\begin{aligned}
& \Delta V=V(n)-V(n-1)<\Delta V_{\text {set }} \\
& \frac{\Delta I}{I(n-1)}=\frac{I(n)-I(n-1)}{I(n-1)}<\Delta I_{\text {set }} \cong \frac{I(n-1)}{N_{p n}}
\end{aligned}
$$

where, $\mathrm{N}_{\mathrm{pn}}$ is the number of parallel module and $\Delta \mathrm{V}_{\text {set }}$ is the predefined voltage range set by the manufacture. The linear function to shift the operating point near the vicinity of global MPP is as follow:

$$
V^{*}=\frac{V_{\text {orms }}}{I_{\text {orms }}} I(n)
$$

The load line algorithm is simple and can be implemented easily on microcontroller. The study in Jun et al. (2014) shows that the load line algorithm performance is satisfactory only for some specific partial shading pattern and in some cases, it misses the global MPP.

\subsection{Fibonacci Search Technique}

The Fibonacci search technique is a searching scheme which reduces the space of sorted array by divide and conquer algorithm (Miyatake et al. 2004). It uses the Fibonacci number to narrow down the search space. By proper modification in Fibonacci technique, it can be used to find the MPP under uniform and nonuniform insolation (Ahmed and Miyatake 2008;
Ramaprabha et al. 2010). The Fibonacci sequence of number is defined by:

$\left\{\begin{array}{c}F_{0}=0 \\ F_{1}=1 \\ F_{n}=F_{n-1}+F_{n-2} \text { for } n \geq 2(n=2,3 \ldots . .)\end{array}\right.$

The Fibonacci search scheme is demonstrated in Fig. 19. The initial range of search space is in between upper $\left(V_{1}\right)$ \& lower $\left(V_{2}\right)$ limit, and approximate points $V_{3}$ and $\mathrm{V}_{4}$ are also chosen. The algorithm is initialized with $\mathrm{V}_{1}$, $V_{2}, V_{3}$ and $V_{4}$ The range is given as:

$a_{i}+b_{i}+a_{i}=A_{i}$
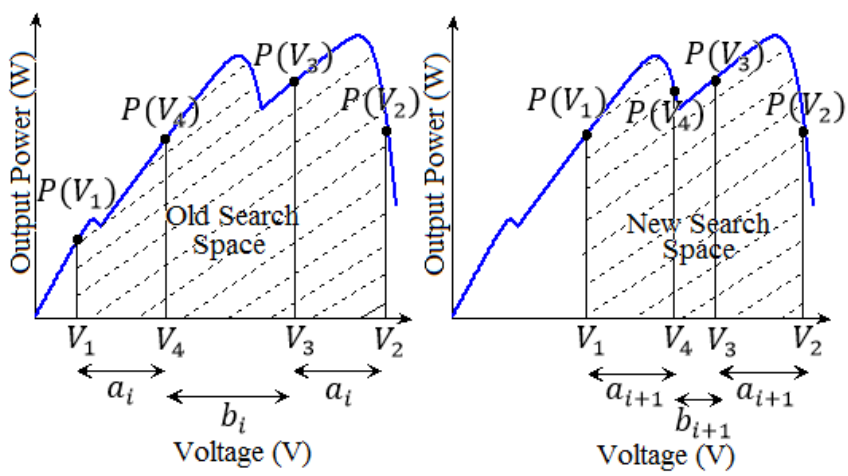

Fig. 19 Sorting of search space in Fibonacci search

The $V_{3}$ and $V_{4}$ are the test point. If power at $V_{3}$ $\left(\mathrm{P}\left(\mathrm{V}_{3}\right)\right)$ is greater than power at $\mathrm{V}_{4}\left(\mathrm{P}\left(\mathrm{V}_{4}\right)\right)$, then search space is shifted to right, otherwise shift it toward left. Now update the search points as, $V_{1}, V_{2}, V_{3}$ and a new value of $V_{4}$ is calculated by using search formula.

$V_{4}=V_{1}+\left(\frac{F_{n-1}}{F_{n}}\right)\left(V_{2}-V_{1}\right)$

where, $F_{n}$ is the Fibonacci number. As shown in Fig. 19, after one iteration, the search space shrink and given by Equation (34).

$a_{i+1}+b_{i+1}+a_{i+1}=a_{i}+b_{i}=A_{i}-a_{i}$

The algorithm for MPPT using Fibonacci search initializes the four points in search space and the search space after each iteration, either shrink toward left or right. At the end of each iteration, $P\left(V_{1}\right)-P\left(V_{2}\right)$ is compared with allowable error (e). And the iteration is terminated, if $\mathrm{P}\left(\mathrm{V}_{1}\right)-\mathrm{P}\left(\mathrm{V}_{2}\right)$ is less than e.

\subsection{PSO MPPT Scheme}

The Particle Swarm Optimization (PSO) is a metaheuristic search approach, which can be used to optimize the complex objective function (Liu et al. 2012). The PSO works on the principle of bird folk searching for the location of the food. The continuous 
change in direction and speed of the bird is depend upon its own best location and the best location among all birds. In PSO, the next position of the particle is influenced by the best solution of the particle and the overall best solution of the neighbours. The particle position is given as:

$x_{i}^{k+1}=x_{i}^{k}+v_{i}^{k+1}$

where $v_{i}^{k+1}$ is the velocity component and it represents next step size. The velocity expression is calculated as:

$v_{i}^{k+1}=w v_{i}^{k}+c_{1} r_{1}\left\{P_{\text {besti }}-x_{i}^{k}\right\}+c_{2} r_{2}\left\{G_{\text {best }}-x_{i}^{k}\right\}$

where $\mathrm{w}$ is the inertial constant, $\mathrm{c}_{1}$ and $\mathrm{c}_{2}$ are the weighting coefficient, $r_{1}$ and $r_{2}$ are the uniform random number $(\epsilon \mathrm{U}(0,1))$, P besti is the individual best position and $G_{\text {besti }}$ is the best position among all particles. The random movement of particle in PSO is shown in Fig. 20.

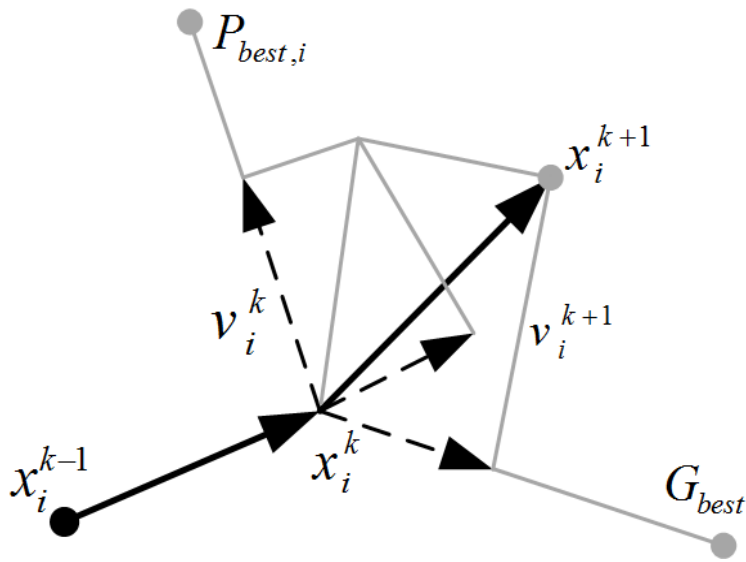

Fig. 20 Particles movement in PSO optimization (Liu et al. 2012)

The PSO MPPT performance does not depend upon the shape of I-V curve. So, it is able to track global MPP for any partial shading conditions. The slow convergence time, selection of appropriate random variable and advanced microcontroller for the implementation of algorithm are the major drawbacks of the conventional PSO. To solve these issues, various adaptive and hybrid PSO techniques are proposed in literature. In Ishaque and Islam (2013), Deterministic PSO is proposed and the velocity of the particle is modified as:

$v_{i}^{k+1}=w v_{i}^{k}+\left\{P_{b e s t i}-x_{i}^{k}\right\}+\left\{G_{b e s t}-x_{i}^{k}\right\}$

Similarly in Lian et al. (2014), the hybrid PSO, which uses P\&O for finding the first local MPP and then PSO is used to track the GMPP. In this technique, search space of PSO is reduced significantly and it improves the overall tracking speed of GMPPT.

\subsection{Distributed MPPT}

The partial shading or uneven distribution of Irradiance increase the PV string losses. The bypass diode across each PV module reduce the effect of partial shading. But, it also complicates the I-V curve of the PV system and requires a complex MPPT for the tracking of GMPP. In Distributed Maximum Power Point Tracking (DMPPT), each PV panel has its own DC-DC converter with proper MPPT controller (Sharma and Agarwal 2014). Due to distributed in nature, MPPTs are able to operate each PV panel at optimal voltage and current value. In case of partial shading, the DMPPT performance is more effective than array level techniques. The basic classification of DMPPT is shown in Fig. 21. The DMPPT can be realized in two ways:
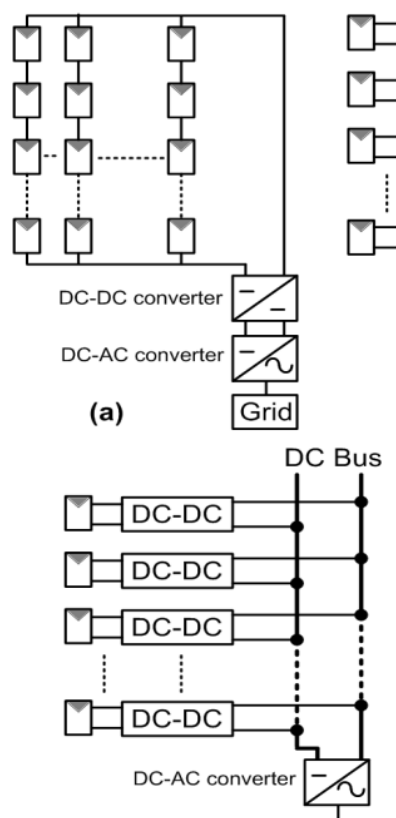

(c)
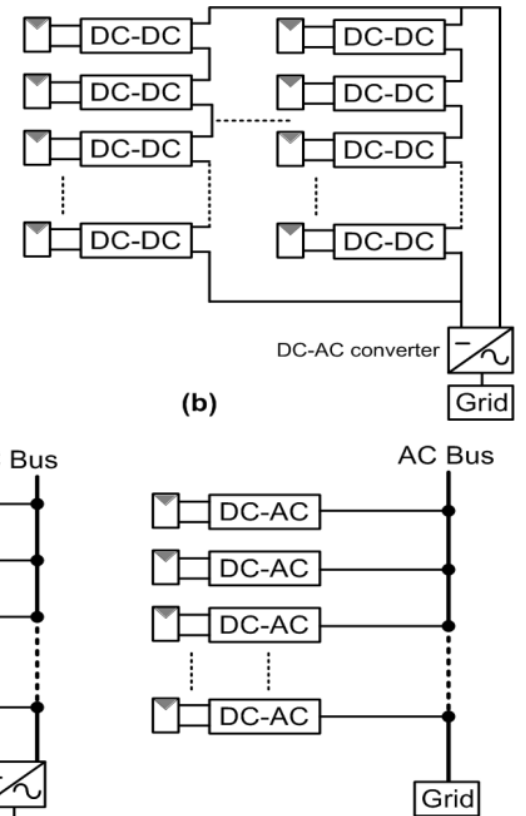

(d)
Fig. 21 DMPPT schemes for power extraction: (a) central MPPT converter, (b) Series Connected DMPPT, (c) Shunt connected DMPPT, and (d) Shunt Micro Inverter configuration.

1. Full Power Dedicated DC-DC Converter DMPPT (FPDC) Fig. 21(b): It is also known as series connected microconverter (SCMC). In this topology, DC-DC converters are connected in cascade manner and perform regular MPPT tracking for each module. Due to its topology, entire power flows through the dedicated converter and it causes extra power loss. Various researches have attempted to improve the performance of FPDC are reported in Sharma and Agarwal (2014), Chan et al. (2014). In 
spite of various modifications in topology, efficiency remain low during partial shading.

2. Compensation Power Dedicated DC-DC Converter MPPT (CPDC) Fig. 21(c): In this technique, each micro converter with individual PV module is directly connected to DC bus (Xiao et al. 2007; Bratcu et al. 2011). Due to parallel configuration of the converter, the effect of partial shading is minimal. The control structure of CPDC is simple, but it requires a high voltage rating converter, which adds the cost of the system.

Sometime, micro inverter configuration is also used to replace central inverter (Xiao et al. 2007). The configuration of micro inverter is shown in Fig. 21(d). The comparative analysis of the DMPPT techniques under different shading condition is performed in [60]. The bar chart of the output power performance of different DMPPT is shown in Fig. 22 and it indicates that DMPPT improve the output power significantly.

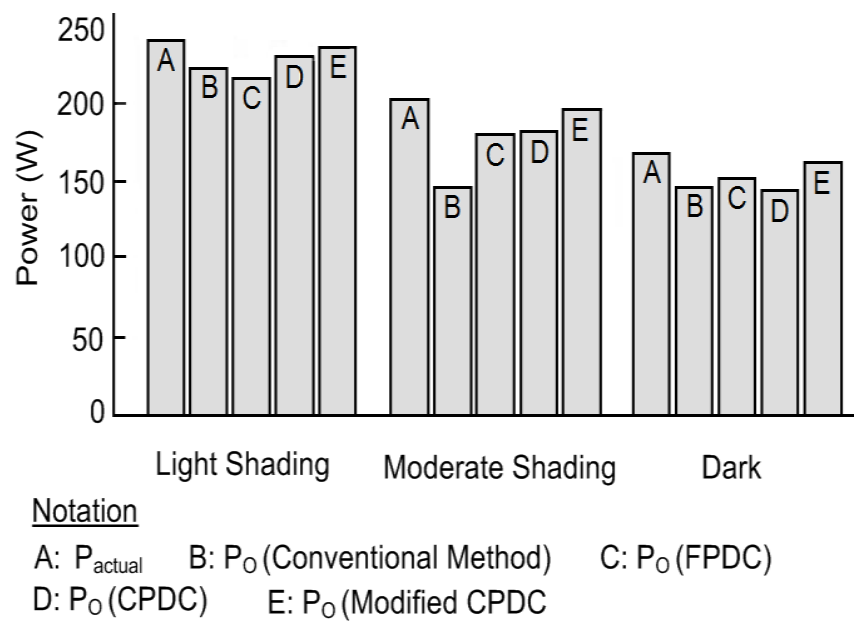

Fig. 22 Comparison of power extracted from the conventional MPPT and DMPPT schemes (Ramaprabha et al. 2010)

\subsection{Fixed Structure Reconfiguration Method}

The PV array structure reconfiguration is another way to reduce the mismatch loss. The four major configurations of PV array are Series-Parallel (SP), Totally Crossed Tied (TCT), Bridge-Link (BL) and Honey Comb (HC) (Villa et al. 2012). The architecture of the different configurations is shown in Fig. 23. The modification in configuration helps to reduce the amount of current flow in bypass diode under mismatch condition. Therefore, the maximum power output in case of TCT, BL and HC configuration is improved. In Villa et al. (2012) and Modballegh \& Jang (2014), different shading patterns are used to check the performance of each configuration. The result in Villa et al. (2012) shows that TCT and BL structure causes improvement in output power by $3.8 \%$ and $2.3 \%$ respectively. It is found that TCT is the best configuration in term of maximum power output under partial shading.

The structure reconfiguration also helps to reduce the effect of partial shading and allow to track global maximum power using conventional MPPT under some shading pattern (Picault et al. 2010). The reconfiguration of $\mathrm{PV}$ array with matrix box to compensate the shaded PV modules with reserve panels is another good solution to reduce partial shading effect. With structure modification, the efficiency of the system is improved, but it also adds the copper loss due to extra wiring and the practical realization is limited due to added complexity in wiring.

Apart from above GMPPT techniques, ANN and terminal voltage measurement based MPPT is also reported in the literature. In Syafaruddin and Hiyamaa (2009), the Irradiance at the corner of the PV array is measured for the estimation of partial shading and for the specific pattern of Irradiance, neural is trained to locate GMPP. Similarly, in Chen et al.(2014), the output voltage at each PV module terminal is measured and it is used to detect the shading and the approximate location of the Global Maximum Power Point.

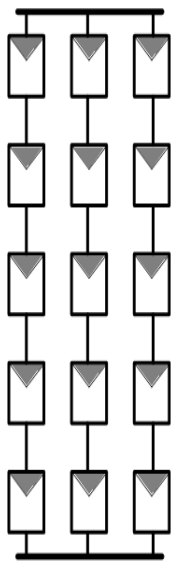

SP

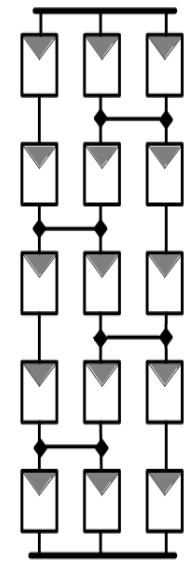

$\mathrm{BL}$

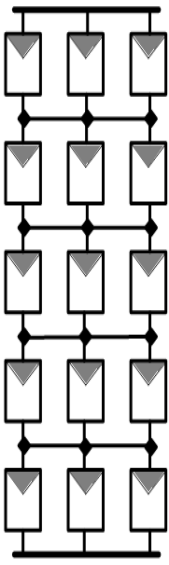

TCT

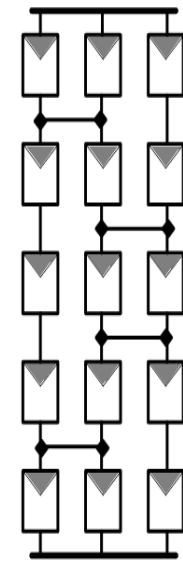

$\mathrm{HC}$
Fig. 23 Wiring diagram of the Series-Parallel, Bridge-Link, Totally Crossed Tied and Honey Comb fixed structure configuration

\section{Comparison and Analysis}

There are a number of available MPPT techniques for solar PV system users. It is required to choose the best MPPT technique, which suits the application needs. In Table 1 and Table 2, an attempt has been made to compare MPPT techniques based on features like control strategy, complexity of implementation, circuit type, cost, merit and demerit etc. The brief description of the comparison criteria of MPPTs is as follow: 
Citation: Sameeullah, M. and Swarup, A. (2016). MPPT Schemes for PV System under Normal and Partial Shading Condition: A Review. Int. Journal of Renewable Energy Development, 5(2),79-94, doi: 10.14710/ijred.5.2.79-94

$\mathrm{P}$ a g e 190

Table 1

Comparison of Different MPPT Techniques for Normal Irradiance

\begin{tabular}{|c|c|c|c|c|c|c|c|c|}
\hline $\begin{array}{c}\text { MPPT } \\
\text { Technique }\end{array}$ & $\begin{array}{c}\text { PV Array } \\
\text { Dependent }\end{array}$ & $\begin{array}{c}\text { Analog } \\
\text { or } \\
\text { Digital }\end{array}$ & $\begin{array}{c}\text { Sensed } \\
\text { Parameters }\end{array}$ & $\begin{array}{l}\text { Parameter } \\
\text { Tuning }\end{array}$ & Complexity & Cost & Merit & Demerit \\
\hline Curve Fitting & Yes & Digital & V or I & Yes & Simple & INEX & Use simple logic & $\begin{array}{l}\text { Continuous power } \\
\text { loss }\end{array}$ \\
\hline $\begin{array}{l}\text { Current } \\
\text { Fraction }\end{array}$ & Yes & Analog & I & Yes & Simple & INEX & $\begin{array}{l}\text { No computation } \\
\text { hardware required }\end{array}$ & $\begin{array}{l}\text { Power loss during } \\
\text { change in weather }\end{array}$ \\
\hline $\begin{array}{l}\text { Voltage } \\
\text { Fraction }\end{array}$ & Yes & Analog & $\mathrm{V}$ & Yes & Simple & INEX & $\begin{array}{l}\text { No computation } \\
\text { hardware required }\end{array}$ & $\begin{array}{l}\text { Power loss during } \\
\text { change in weather }\end{array}$ \\
\hline Lookup Table & Yes & Digital & $\mathrm{V}, \mathrm{I}$ or $\mathrm{G}, \mathrm{T}$ & Yes & Simple & INEX & Simple logic & $\begin{array}{l}\text { Periodic tuning } \\
\text { required }\end{array}$ \\
\hline SSC & No & Both & $\mathrm{V}, \mathrm{I}$ & Yes & Simple & INEX & $\begin{array}{l}\text { Reduce Power loss in } \\
\text { DC-DC conversion }\end{array}$ & $\begin{array}{l}\text { Not suitable for } \\
\text { Standalone } \\
\text { application }\end{array}$ \\
\hline $\begin{array}{l}\text { Current / } \\
\text { Voltage } \\
\text { Feedback }\end{array}$ & Yes & Both & V or I & No & Simple & INEX & Easy to implement & $\begin{array}{l}\text { Power loss due to } \\
\text { change in weather }\end{array}$ \\
\hline P\&O & No & Both & $\mathrm{V}, \mathrm{I}$ & No & Medium & $\mathrm{EX}$ & $\begin{array}{l}\text { Good tracking } \\
\text { capability }\end{array}$ & $\begin{array}{l}\text { Continuous } \\
\text { oscillation and } \\
\text { tracking speed }\end{array}$ \\
\hline INC & No & Digital & $\mathrm{V}, \mathrm{I}$ & No & Complex & EX & $\begin{array}{l}\text { Low oscillation near } \\
\text { MPP }\end{array}$ & $\begin{array}{l}\text { Complexity in } \\
\text { implementation }\end{array}$ \\
\hline $\begin{array}{l}\text { Parasitic } \\
\text { Capacitance }\end{array}$ & No & Digital & $\mathrm{V}, \mathrm{I}$ & Yes & Medium & $\mathrm{EX}$ & Refine form of INC & $\begin{array}{l}\text { Detail knowledge of } \\
\text { system is essential } \\
\text { for implementation }\end{array}$ \\
\hline $\begin{array}{l}\text { Sliding Mode } \\
\text { Control }\end{array}$ & No & Digital & V or I & No & Complex & $\mathrm{EX}$ & $\begin{array}{l}\text { Fast convergence } \\
\text { speed }\end{array}$ & $\begin{array}{l}\text { Measurement of } \\
\text { sensor parameters }\end{array}$ \\
\hline FLC & Yes & Digital & $\mathrm{V}, \mathrm{I}$ or $\mathrm{G}, \mathrm{T}$ & Yes & Complex & EX & $\begin{array}{l}\text { Good response and } \\
\text { little oscillation near } \\
\text { MPP }\end{array}$ & $\begin{array}{l}\text { Complexity in } \\
\text { implementation and } \\
\text { selection of proper } \\
\text { range of operation }\end{array}$ \\
\hline ANN & Yes & Digital & $\mathrm{V}, \mathrm{I}, \mathrm{G}$ & Yes & Complex & EX & $\begin{array}{l}\text { Good response and } \\
\text { less oscillation near } \\
\text { MPP }\end{array}$ & Parameter tuning \\
\hline $\begin{array}{l}\text { Adaptive } \\
\text { P\&O }\end{array}$ & Yes & Digital & $\mathrm{V}, \mathrm{I}$ & Yes & $\begin{array}{l}\text { Medium / } \\
\text { Complex }\end{array}$ & EX & $\begin{array}{l}\text { Fast convergence } \\
\text { speed }\end{array}$ & $\begin{array}{l}\text { Advanced } \\
\text { microcontroller is } \\
\text { required for } \\
\text { implementation }\end{array}$ \\
\hline Hybrid MPPT & Can't say & Digital & $\mathrm{V}, \mathrm{I}$ & Yes & $\begin{array}{c}\text { Medium / } \\
\text { Complex }\end{array}$ & $\mathrm{EX}$ & $\begin{array}{l}\text { Fast convergence } \\
\text { speed }\end{array}$ & $\begin{array}{l}\text { Higher cost of } \\
\text { implementation }\end{array}$ \\
\hline
\end{tabular}

\# V: Voltage, I: Current, G: Irradiance, T: Temperature, EX: Expensive, INEX: Inexpensive

A. Sensor Requirement: The different measurement quantities such as voltage, current, irradiance or temperature are often required for MPPT tracking. Most of the time, the voltage and current data are required for MPPT implementation, but in some case, apart from voltage and current data, irradiance and temperature variable are also required. The measurement of voltage is easy and cheap, whereas the current sensor is costly and implementation requires complex circuit.

B. Type of Circuit: The two possible types of circuitry used for MPPT techniques are analog and digital. The best suited circuitry depends upon the application requirement and comforts in implementation.
C. According to Cost: The cost comparison of MPPT techniques is not possible, unless hardware is implemented. In this paper, cost is compared based on the type of circuitry, number of sensor requirements, software used and the complexity of algorithms.

The selection of MPPT for solar PV system is totally depends upon the type of application. Some of the basic applications of PV system are solar gadgets, off grid home solar system, grid connected PV system, solar vehicle and the two sided roof top PV system, etc. It is observed that proper selection of MPPT is essential, as it indirectly increase the cost of the PV system and affect the system performance. After the comparison of MPPTs and taking consideration of application requirements, some of the good MPPTs are 
Voltage / Current Fraction, P\&O, INC, Adaptive P\&O, SSC and FLC etc. The Voltage Fraction MPPT is good for low cost solar devices like solar lantern. Similarly, $\mathrm{P} \& O$ and INC are efficient for the off grid PV system. The FLC and adaptive techniques are acceptable for large PV system.

The PV system in Matlab Simulink environment with PV panel of $200.3 \mathrm{~W}_{\mathrm{p}}\left(\mathrm{KC} 200 \mathrm{GT}, \mathrm{V}_{\text {ocn }}=32.9 \mathrm{~V}\right.$, $\mathrm{I}_{\mathrm{scn}}=8.21 \mathrm{~A}, \mathrm{~V}_{\mathrm{mpp}}=26.3 \mathrm{~V}, \mathrm{I}_{\mathrm{mpp}}=7.61 \mathrm{~A}, \mathrm{a}=1.3, \mathrm{R}_{\mathrm{s}}=415.4 \Omega$ and $\mathrm{R}_{\mathrm{ph}}=0.22 \Omega$ ), DC-DC Buck converter and battery of $12 \mathrm{~V}$, is used to study the MPPTs capability. The Simulink model used for the analysis is shown in Fig.24. The simulation result of four major MPPT are shown in Fig. 26, Fig. 27 and Fig. 28. The Irradiance signal used for the analysis is shown in Fig. 25. The Irradiance signal is suitable for the study of MPPT under slow and fast varying Irradiance.

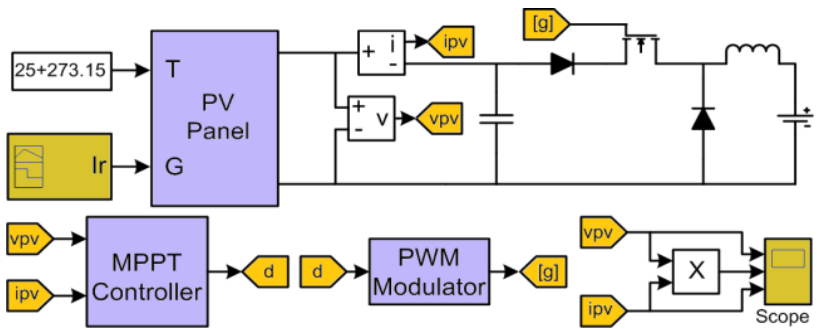

Fig. 24 Simulink model of solar PV system for MPPT controller testing

As shown in Fig. 26, the Fraction Voltage MPPT is able to track MPP, but the MPPT requires continuous updating of $\mathrm{V}_{\text {oc }}$ and the significant amount of power is lost during open circuit voltage measurement. The open circuit voltage changes significantly with change in temperature. Therefore, continuous updating of $\mathrm{V}_{\mathrm{oc}}$ has more significant under varying temperature. The output power analysis of the circuit with $\mathrm{P} \& 0$ and INC is shown in Fig. 27. As shown in figure, both techniques have a good capability to track MPP, but the operating point continuously fluctuate near MPP. As compared to INC MPPT, the P\&O MPPT faces more fluctuation. The output power analysis of Fig. 28 shows that FLC has a good tracking capability and also there is a reduced power fluctuation near MPP. It is found that the response of adaptive $P \& O$ is approximately similar to FLC.

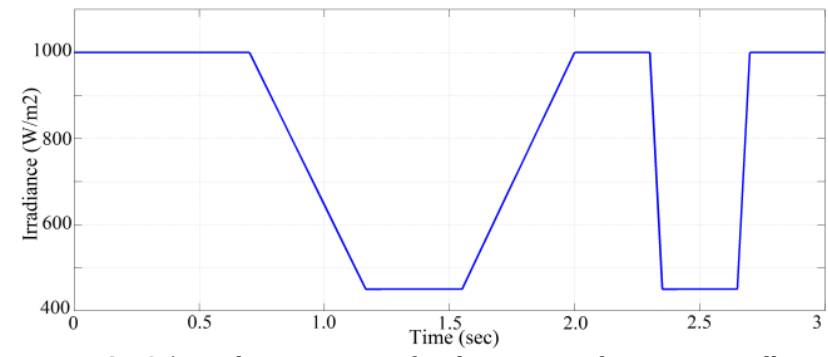

Fig. 25 Irradiance pattern for the testing of MPPT controller

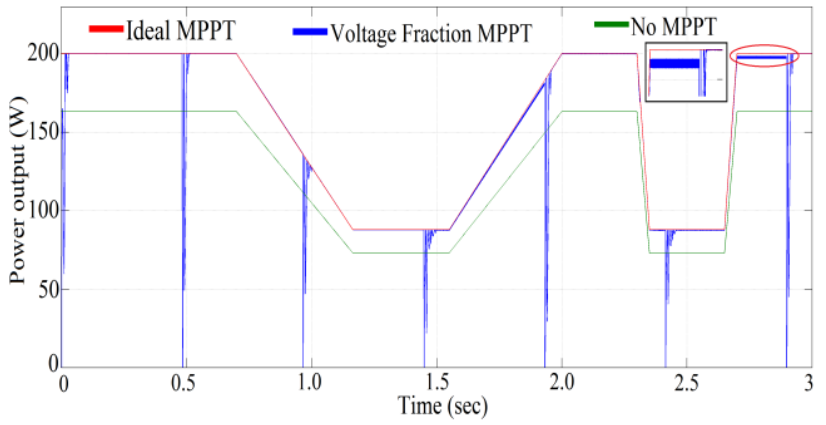

Fig. 26 Power output response for Voltage Fraction MPPT

Table 2.

Comparison of Different MPPT Techniques for Partial Shading Condition

\begin{tabular}{|c|c|c|c|c|c|c|c|c|}
\hline MPPT Techique & $\begin{array}{l}\text { PV Array } \\
\text { Dependent }\end{array}$ & $\begin{array}{c}\text { Analog or } \\
\text { Digital }\end{array}$ & $\begin{array}{c}\text { Sensed } \\
\text { Parameter }\end{array}$ & $\begin{array}{l}\text { Parameter } \\
\text { Tuning }\end{array}$ & Complexity & Cost & $\begin{array}{l}\text { Convergence } \\
\text { Speed }\end{array}$ & Application \\
\hline $\begin{array}{l}\text { Simple power } \\
\text { curve scanning }\end{array}$ & No & Digital & V, I & & Simple & Low & Slow & $\begin{array}{l}\text { Two sided roof } \\
\text { PV system }\end{array}$ \\
\hline $\begin{array}{l}\text { Power curve } \\
\text { slope detection }\end{array}$ & No & Digital & V, I & No & Medium & Medium & Medium & - \\
\hline $\begin{array}{l}\text { Load Line } \\
\text { Matching }\end{array}$ & No & Digital & V, I & No & Medium & Medium & Medium & - \\
\hline Fibonacci Search & Yes & Digital & V, I & Yes & Complex & High & Medium & $\begin{array}{l}\text { For simple } \\
\text { application }\end{array}$ \\
\hline PSO & Yes & Digital & V, I & Yes & Complex & High & Fast & $\begin{array}{l}\text { Experimental } \\
\text { study }\end{array}$ \\
\hline DMPPT & No & Both & V, I & No & Medium & High & Fast & $\begin{array}{l}\text { Hybrid vehicle, } \\
\text { high efficiency } \\
\text { system }\end{array}$ \\
\hline $\begin{array}{l}\text { Fixed Structure } \\
\text { Reconfiguration }\end{array}$ & Yes & Both & V, I & No & Simple & High & - & $\begin{array}{l}\text { For analysis } \\
\text { and study, } \\
\text { small system }\end{array}$ \\
\hline
\end{tabular}




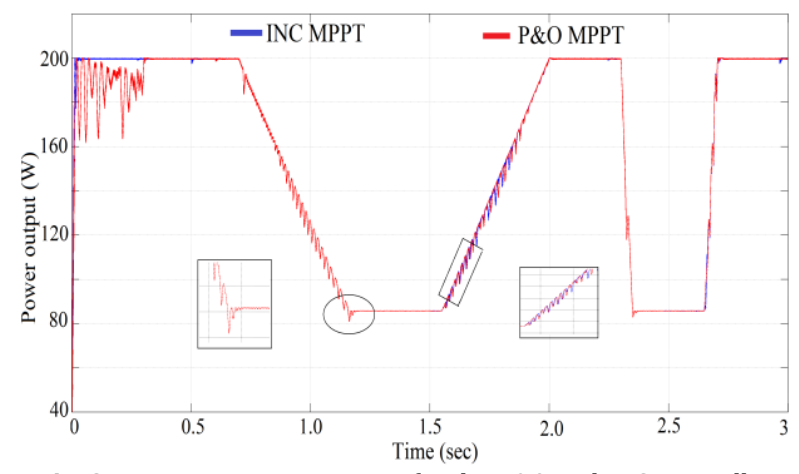

Fig. 27 Power output response for the P\&O and INC controller

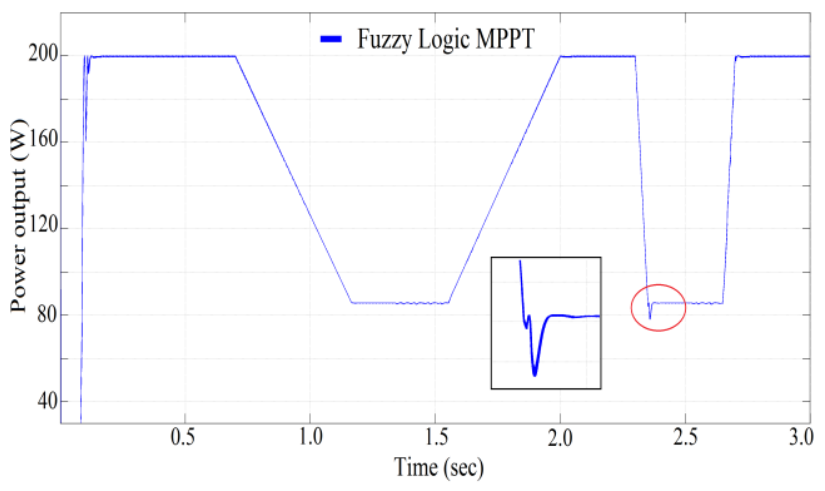

Fig. 28 Power output response for Fuzzy Logic MPPT controller

The MPPT with capability to work under partial shading has limited application. Some of the important applications which need GMPPT are solar Vehcile, dual slope roof top system and building integrated PV system, etc. For the acceptability, GMPPT must be reliable, efficient, and cost effective. The power curve scanning technique is good enough for the large PV system. The Sunny Boy 10000TL (commercial inverter) uses dual MPPT with OptiTrack (Power Curve Scanning). The partial shading pattern shown in Fig. 29 is used for the proper demonstration of GMPPT technique. The power output pattern in case of Power Curve Scanning GMPPT is depicted in Fig. 30. It shows that the scanning time is approximately same for different partial shading conditions. The simulation results for Power Slope Detection GMPPT is presented in Sobhana et al. (2013). Figure 31 shows the simulation of modified Power Slope Detection GMPPT. Fig 31 shows that the Power Slope Detection method improves the tracking time and also reduces the overall fluctuation in output power.

The DMPPT and intelligent PSO are acceptable only for the application with continuous partial shading like building integrated PV. A module integrated DMPPT is very effective for unpredicted environment condition, but it is still not in trend due to higher cost of power electronic circuit and reliability issues. Overall, for achieving good efficiency, the proper choice of MPPT is essential.

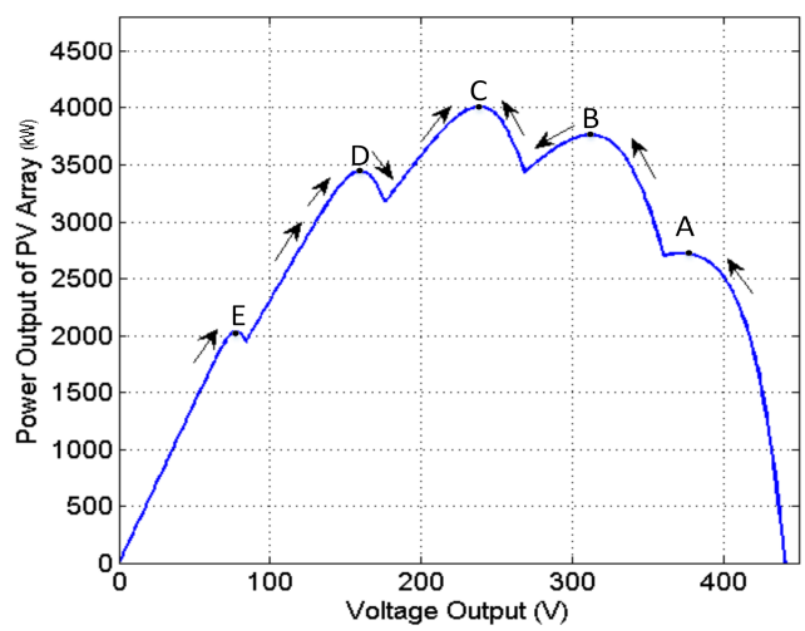

Fig. 29 The P-V curve for the demonstration of Power slope technique algorithm

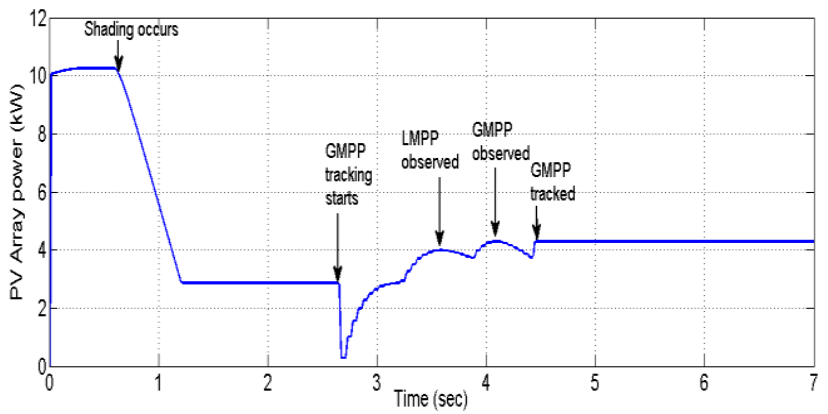

Fig. 30 The output power of PV array for the Power Curve Scanning technique

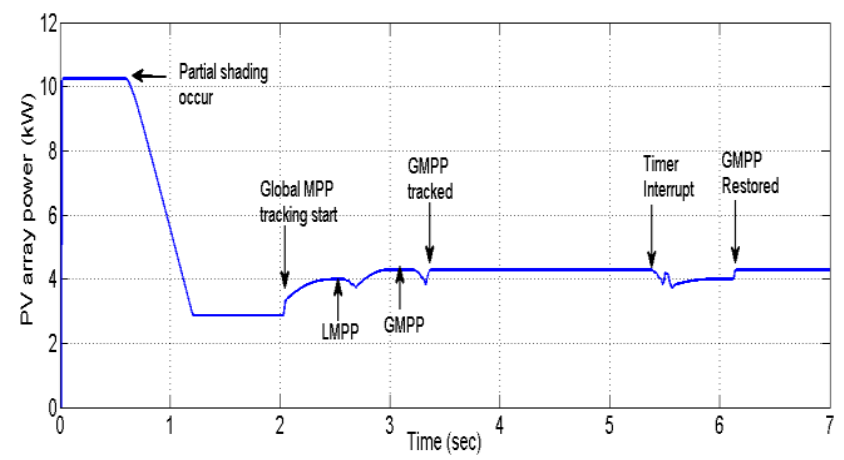

Fig. 31 The output power of PV array for the modified Power Slope Detection GMPPT technique

The detail analysis of simulation work is beyond the scope of this work. For better understanding, the simulation model used for the analysis of MPPT developed by author, has been made available for download at:

https://sites.google.com/site/renewablezone/simulat ion-model.

\section{Conclusions}

The prominent techniques of MPPT are discussed in this paper. It may be used as tutorial material on solar MPPT. Also, an attempt has been made to describe the important GMPPT techniques with sufficient details. A comprehensive comparative analysis has been 
contributed in this paper considering performance, cost, complexity of circuit and other parameters of MPPT. The results of this analysis will be helpful for proper selection of MPPT method. The generated power performance through few MPPT controllers has been illustrated with the help of simulation excercise. This also provides better understanding through numerical comparison. This review work has also presented a brief analysis and comparison of MPPT techniques for partial shading conditions. This paper may be useful for solar PV system manufacturer and solar inverter designer.

\section{References}

Abdourraziq, S., \& El. Bachtiri Rachid (2014) A perturb and observe method using fuzzy logic control for PV pumping system. International Conference on Multimedia Computation and Systems, Marrakech, 1608-1612.

Adly, M., El-Sherif, H., \& Ibrahim, M. (2011) Maximum Power Point Tracker for a PV cell using a fuzzy agent adapted by the Fractional open circuit voltage technique. IEEE International Conference on Fuzzy System, Taipei, 1918-1922.

Ahmad, J. (2010) A fractional open circuit voltage based maximum power point tracker for photovoltaic arrays. International Conference on Soft Technology and Engineering, San Juan, 247250

Ahmed, N.A., and Miyatake, M. (2008) A novel maximum power point tracking for photovoltaic applications under partially shaded insolation conditions. Electric Power System Research, 78, 777-784.

Altas, I.H., \& Sharaf, A.M. (1996) A novel on-line MPP search algorithm for PV arrays. IEEE Transactions on Energy Conversions, 11 (4), 748-754.

Atiqi, M.A., Zainuri, M., Amran, M., Radzi, M., Che Soh, A., \& Rahim, A.B. (2014) Development of adaptive perturb and observe-fuzzy control maximum power point tracking for photovoltaic boost dc-dc converter. IET Renewable Power Generation, 8 (2), 183 194.

Aureliano, M., Brito, G., Galotto, L., Sampaio, L.P., Melo, G.A., \& Canesin, C.A. (2013) Evaluation of the main MPPT techniques for photovoltaic applications. IEEE Transactions on Industrial Electronics, 60 (3), 1156-1167.

Brambilla, A., Gambarara, M., Garutti, A., \& Ronchi, F. (1999) New approach to photovoltaic arrays maximum power point tracking. $30^{\text {th }}$ Annual IEEE Power Electronics Specialist Conference, Charleston, 632-637.

Bratcu, A.I., Munteanu, I.M., Bacha, S., Picault, D., \& Raison, B., (2011) Cascade DC-DC converter photovoltaic systems: power optimization issues. IEEE Transactions on Industrial Electronics, 58 (2), 403-411.

Cabal, C., Martinez-Salamero, L., Seguir, L., \& Alonso C. (2004) Maximum power point tracking based on sliding-mode control for output-series connected converters in photovoltaic systems. IET Power Electronics, 7 (4), 914-923.

Chen K., Tian, S., Cheng, Y., \& Bai, L. (2014) An improved MPPT controller for photovoltaic system under partial shading condition. IEEE Transactions on Sustainable Energy, 5 (3), 978985.

Chen, C.W., Chen, K.H., \& Chen, Y.M. (2014) Modeling and controller design of an autonomous PV module for DMPPT PV systems. IEEE Transactions on Power Electronics, 29 (9), 4723-4732.

Chen, Y., \& Smedley, K.M. (2004) A cost-effective single-stage inverter with maximum power point tracking. IEEE Transactions on Power Electronics, 19 (5), 1289-1294.

Ding, K., Bian, X.G., Liu, H.H, \& Peng, T. (2012) A matlab-simulinkbased PV module model and its application under conditions of nonuniform Irradiance. IEEE Transactions on Energy Conversion, 27 (4), 864-872.

Dolara, A., Lazaroiu, G.C., Leva, S., \& Manzolini, G. (2013) Experimental investigation of partial shading scenarios of $\mathrm{PV}$ (photovoltaic) modules. Energy, 55, 466-475.

Esram, T., \& Chapman, P. L (2007) Comparison of photovoltaic array maximum power point tracking techniques. IEEE Transactions on Energy Conversion, 22 (2), 439-449.

Farhat, S., Alaoui, R., Kahaji, A., \& Bouhouch, L. (2013) Estimating the photovoltaic MPPT by artificial neural network. International Conference on Renewable and Sustainable Energy, Ouarzazate, 49-53.

Hajighorbani, S., Radzi, M.A.M., Ab Kadir, M.Z.M, Shafie, S., Khanaki, R., \& Maghami, M.R. (2014) Evaluation of fuzzy logic subsets effects on maximum power point tracking for photovoltaic system. International Journal of Photoenergy, 2014, 1-13.

Hohm, D.P, \& Roop, M.E. (2000) Comparative study of maximum power point tracking algorithms using an experimental, programmable, maximum power point tracking test bed. $28^{\text {th }}$ IEEE Photovoltaic Specialists Conference, Anchorage, 16991702.

Hua, C., Lin, J., \& Sen, C. (1998) Implementation of DSP-controlled photovoltaic system with peak power tracking. IEEE Transactions on Industrial Electronics, 45 (1), 99-107.

Iqbal, A., Abu-Rub, H., \& Ahmed, S.M. (2010) Adaptive neuro-fuzzy inference system based maximum power point tracking of a solar PV module. IEEE International Energy Conference, Manama, 51-56.

Ishaque, K., and Islam, Z. (2013) A Deterministic particle swarm optimization maximum power point tracker for Photovoltaic system under partial shading condition. IEEE Transactions on Industrial Electronics, 60 (8) 3195-3206.

Ishaque, K., Salam, Z., \& Syafruddin (2011) A comprehensive MATLAB simulink PV system simulator with partial shading capability based on two diode model. Solar Energy, 85 (9), 2217-2227.

Ji, Y.H., Jung, D.Y., Kim, J.G., Kim, J.H., Lee, T.W., \& Won, C.Y. (2011) A real Maximum power point tracking method for mismatching compensation in PV array under partially shaded conditions. IEEE Transactions on Power Electronics, 26 (4) 1001-1009.

Jiang, L.L., Nayanasiri, D.R., Maskell, D.L., \& Vilathgamuwa, D.M. (2013) A simple and efficient hybrid maximum power point tracking method for PV systems under partially shaded condition. 39th Annual Conference of the IEEE Industrial Electronics Society, Vienna, 1513-1518.

Jie, D., Chun-jiang, Z., \& Yan-bang, L. (2012) Comparison of duty ratio perturbation \& observation and reference voltage perturbation \& observation methods applied in MPPT. IEEE $7^{\text {th }}$ International Power Electronic and Motion Control Conference, 1358-1362.

Jun Qi, Zhang, Y., \& Chen, Y. (2014) Modeling and maximum power point tracking (MPPT) method for PV array under partial shaded conditions. Renewable Energy, 66, 337-345.

Kajaer, S.B. (2013) Evaluation of the "hill climbing" and the "incremental conductance maximum power points trackers for photovoltaic power systems. IEEE Transactions on Energy Conversion, 27 (4), 922-929.

Karanjkar, D.S., Chatterji, S., \& Kumar, A. (2013) An improved current feedback based maximum power point tracking controller for solar photo-voltaic system. International Conference on Microelectronics, Communication and Renewable Energy, Kanjirapally, 1-6.

Khatib, T.T.N., Mohamed, A., \& Amim, N. (2010) An Improved indirect maximum power point tracking method for standalone photovoltaic systems. 9th WSEAS International Conference on Application of Electrical Engineering, Penang, 56-62, 23-25.

Kollimalla, S.K., \& Mishra, M.K. (2014) A novel adaptive P\&O MPPT algorithm considering sudden changes in the irradiance. IEEE Transactions on Industrial Electronics, 29 (3), 602-610.

Koutroulis, E., \& Blaabjerg, F. (2012) A new technique for tracking the global maximum power point of PV arrays operating under partial shading conditions. IEEE Journal of Photovoltaics, 2 (2), 184-190. 
Kulaksiz, A.A., \& Akkaya, R. (2012) A genetic algorithm optimized ANN based MPPT algorithm for a stnad-alone PV system with induction motor drive. Solar Energy, 86, 2366-2375.

Kumar, A., Gomathinayagam, S., Giridhar, G., Mitra, I., Vashita, R., Meyer, R., Schwandt, M. \& Chhatbar, K. (2014) Field experiences with operation of solar radiation resource assessment stations in India. Energy Procedia, 49, 2351-2361.

Lee, K.J., \& Kim, R.Y. (2012) An adaptive maximum power point tracking scheme based on a variable scaling factor for photovoltaic systems. IEEE Transactions on Energy Conversion, 27 (4), 1002-1008.

Leedy, A.W., \& Garcia, K.E. (2013) Approximation of P-V characteristic curves for use in maximum power point tracking algorithms. 45th Southeastern Symposium on System Theory, Waco, 88-93.

Lian, K.L., Jhang, J.H., \& Tian, I.S. (2014) A maximum power point tracking method based on perturb - and - observe combined with particle swarm optimization, IEEE Journal of Photovoltaics, 4 (2), 626-633.

Lin, W., Hong, C., \& Chen, C.H. (2011) Neural-network-based MPPT control of a stand-alone hybrid power generation system. IEEE Transactions on Power Electronics, 26 (12), 3571-3581.

Liu, Y.H., Huang, S.C., Huang, J.W., \& Liang, W.C. (2012) A particle swarm optimization-based maximum power point tracking algorithm for PV systems operating under partially shaded conditions. IEEE Transactions on Energy Conversion, 27 (4), 1027-1035.

Lobera, D.T., \& Valkealahti, S. (2014) Inclusive dynamic thermal and electric simulation model of solar PV systemsunder varying atmospheric conditions. Solar Energy, 105, 632-647.

Mamarelis, M., Petrone, G., \& Spagnuolo, G. (2014) Design of slidingmode-controlled SSEPIC for PV MPPT applications. IEEE Transactions on Industrial Electronics, 61 (7), 3387-3398.

Masoum, M.A.S., Dehbonei, H., \& Fuchs, E.F. (2002) Theoretical and experimental analyses of photovoltaic systems with voltage and current based MPPT. IEEE Transactions on Energy Conversion, 17 (4), 514-522.

Mastromauro, R.A., Liserre, M. \& Dell'Aquila, A. (2012) Control issues in single-stage photovoltaic systems: MPPT, current and voltage control. IEEE Transactions on Industrial Informatics, 8 (2), 241-254

Mei, Q., Shan, M., Liu, L. \& Guerrero, J.M. (2011) A novel improved variable step-size incremental-resistance MPPT methods for PV systems. IEEE Transactions on Industrial Electronics, 58 (6), 2427-2434.

Miyatake, M., Inada, T., Hiratsuka, I., Zhao, H. Otsuka, H. and Nakano, M. (2004) Control characteristics of a Fibonacci - search based maximum power point tracker when a photovoltaic array is partially shaded. $4^{\text {th }}$ International Power Electronics and Motion Control Conference, Xi'an, 816-821.

Modballegh, S., \& Jang, J. (2014) Modeling, prediction, and experimental validations of power peaks of PV arrays under partial shading conditions. IEEE Transactions on Sustainable Energy, 5 (1) 293-300.

Mohanty, P., Bhuvaneswari, G., Balasubremanian, R., \& Dhaliwal, N.K. (2014), MATLAB based modeling to study the performance of different techniques used for solar PV system under various operating conditions. Renewable and Sustainable Energy Reviews, 38, 581-593.

NREL (2014) Research cell efficiency records 2014 http://www.nrel.gov/ncpv/pdfs/cell efficiency explanatory no tes.pdf

Ocran, T.A., Junyi, C., Binggang, C., \& Xinghua, S. (2005) Artificial neural network maximum power point tracker for solar electric vehicle. Tsinghua Science and Technology, 10 (2), 204-208.

Patel, H., \& Agarwal, V. (2008) Matlab-based modeling to study the effects of partial shading on PV array characteristics. IEEE Transactions on Energy Conversion, 23 (1), 302-310.
Patel, H., \& Agarwal, V. (2008) Maximum power point tracking scheme for PV systems operating under partially shaded conditions. IEEE Transactions on Industrial Electronics, 55 (4), 1689-1698.

Piao, Z.G., Gong, S.J., An, Y.H., \& Bae Cho, G. (2013) A study on the PV simulator using equivalent circuit model and look-up table hybrid method. International Conference on Electrical Machines and Systems, Busan, 2128-2131.

Picault, D., Raison, B., Bacha, S., Aguilera, J., \& Casa, J.D.L. (2010) Changing photovoltaic array interconnections to reduce mismatch losses: a case study. $9^{\text {th }}$ International Conference on Environment and Electrical Engineering, 37-40.

Ramaprabha, R., Mathur, B., Ravi, A., \& Aventika, S. (2010) Modified Fibonacci search based MPPT scheme for SPVA under partial shaded conditions. International Conference on Emerging Trends in Engineering and Technology, Goa, 379-384.

Rawat, R., \& Chandel, S.S. (2013) Review of Maximum Power Point Techniques for Solar Photovoltaic Systems. Energy Technologies, 1 (8), 438-448.

Safari, A., \& Maekhilef, S. (2011) Simulation and hardware implementation of incremental conductance MPPT using CUK converter. IEEE Transactions on Industrial Electronics, 58 (4), 1154-1161.

Salas, V., Olias, E., Barado, A., \& Lazaro, A. (2006) Review of the maximum power point tracking algorithms for stand-alone photovoltaic system. Solar Energy Materials \& Solar Cells, 90 (11), 1555-1578

Sera, D., Mathe, L., Kerekes, T., Viorel, S., \& Teodorescu, R. (2013) On the perturb-and-observe and incremental conductance MPPT for PV systems. IEEE Journal of Photovoltaics, 3 (3), 1070-1078.

Shah, N., \& Chudamani, R., (2012) A novel algorithm for global peak power point tracking in partially shaded grid-connected PV system. IEEE International Conference on Power and Energy, Malaysia, 558-563.

Sharma, P., and Agarwal, V. (2014) Exact maximum power point tracking of grid-connected partially shaded PV source using current compensation concept. IEEE Transactions on Power Electronics, 29 (9), 4684-4692.

Sobhana, G., Sornadeepika, P., \& Ramaprabha, R. (2013) Global maximum power point tracking of photovoltaic array under partial shaded conditions. International Journal of Engineering Research, 2 (2), 219-223.

Subidhi, B., \& Pradhan, R. (2012) A comparative study on solar array parameter extraction methods. Inderscience International Journal of Renewable Energy Technolgy, 3, 295-315.

Syafaruddin, Karatepe, E., \& Hiyama, T. (2009) Artificial neural network-polar coordinator fuzzy controller based maximum power point tracking control under partially shaded conditions. IET Renewable Power Generation, 3 (2), 239-253.

Villa, L.F.L., Picault, D., Raison, B., Bacha, S., \& Labonne, A. (2012) Maximizing the power output of partially shaded photovoltaic plants through optimization of the interconnections among its modules. IEEE Journal of Photovoltaics, 2, (2), 154-163.

Villalva, M.G., Gazoli, J.F, \& Filho, E.R. (2009) Comprehensive Approach to modeling and simulation of photovoltaic arrays. IEEE Transactions on Power Electronics, 24 (5), 1198-1208.

Xiao Li, Yaoyu Li, \& Seem, J.E. (2013) Maximum power point tracking for photovoltaic system using adaptive extremum seeking control. IEEE Transactions on Control Systems and Technology, 21 (6), 2315-2322.

Xiao, W., Ozog, N., \& Dunford, W.G. (2007) Topology study of photovoltaic interface for maximum power point tracking. IEEE Transactions on Industrial Electronics, 54 (3), 2007.

Zhang, F., Thanapalan, K., Procter, A., Carr, S., \& Maddy, J. (2013) Adaptive hybrid Maximum Power Point Tracking method for a photovoltaic system. IEEE Transactions on Energy Conversion, 28 (2), 353-360. 